\title{
Heat Transfer Performance of Fruit Juice in a Heat Exchanger Tube Using Numerical Simulations
}

\author{
Juan Ignacio Córcoles ${ }^{1,2, *}$, Ernesto Marín-Alarcón ${ }^{1}$ and Jose Antonio Almendros-Ibáñez ${ }^{1,2}$ (I) \\ 1 Escuela Técnica Superior de Ingenieros Industriales, Dpto. de Mecánica Aplicada e Ingeniería de Proyectos, \\ Castilla-La Mancha University, Campus universitario s/n, 02071 Albacete, Spain; \\ ernesto.marin@alu.uclm.es (E.M.-A.); jose.almendros@uclm.es (J.A.A.-I.) \\ 2 Renewable Energy Research Institute, Section of Solar and Energy Efficiency, C/de la Investigación s/n, \\ 02071 Albacete, Spain \\ * Correspondence: juanignacio.corcoles@uclm.es; Tel.: +34-967599200 (ext. 2453)
}

Received: 27 September 2019; Accepted: 11 January 2020; Published: 16 January 2020

check for updates

\begin{abstract}
Enhancing heat transfer rates in heat exchangers is essential in many applications, such as in the food industry. Most fluids used in the food industry are non-Newtonian, whose viscosity is not uniform, and depends on the shear rate and temperature gradient. This is important in the selection of equipment and type of processing. The aim of this work was to numerically simulate, with a non-Newtonian fluid in laminar regime, the heat transfer process in a tube with a curved elbow. The numerical model was validated with published correlations using water as heat transfer fluid. A commercially available fruit juice was used as a non-Newtonian fluid. Its rheological properties were measured using a Modular Compact Rheometer, as well as the activation energy. The difference between outlet temperature and inlet temperature was higher for the laminar simulation (approximately $4{ }^{\circ} \mathrm{C}$ ) than for the turbulent one (approximately $0.7^{\circ} \mathrm{C}$ ). The highest dynamic viscosity values were found at the centre of the pipe (between 0.05 and $0.09 \mathrm{~Pa} \cdot \mathrm{s}$ ), with the lowest values at the wall $(0.0076 \mathrm{~Pa} \cdot \mathrm{s})$. This behaviour is explained by the pseudoplastic condition of the fruit juice. The activation energy did not yield high values, showing a moderate viscosity variation with the temperature change.
\end{abstract}

Keywords: computational fluid dynamics; heat transfer; rheometer; non-newtonian fluid

\section{Introduction}

In the food industry, it is important to determine the flow properties of fluid foods and their behaviour because it is related to the power requirements for the pumping and sizing of pipes during processing. In these cases, it is a key aspect to determine the rheological properties when selecting the equipment and type of processing, and to understand the flow pattern and the heat transfer performance. Most fluid foods used in the industry are non-Newtonian, where the fluid viscosity is not uniform and depends on the shear rate and temperature gradient. To characterise the flow behaviour of such fluids, several mathematical models can be used, such as the Power-Law model, the Cross model, the Bingham model, the Carreau model or the Herschel-Bulkley model [1]. In fluid foods, such as juices, the most common mathematical method is the Power-Law model.

Several studies have focused on analysing the rheological properties of fluid foods. Ibarz et al. [2] analysed the rheological behaviour of two different redcurrant juices using three models (Newtonian model, Power-Law model and Herschel-Bulkley) to define the relationship between shear stress and shear rate. They concluded that, for redcurrant juices containing pectins, the Power-Law model better described their rheological behaviour. Other studies, such as that by Chin et al. [3], modelled the rheological behaviour of pomelo juice concentrates for a temperature range between 6 and $75^{\circ} \mathrm{C}$. They 
obtained good results using the non-Newtonian Power-Law model. Belibağli and Dalgic [4] studied the rheological behaviour of sour-cherry juice, as well as the effect of soluble solids concentration and temperature on flow behaviour. In their study, they used Power-Law model and exponential model to study the effect of concentration on the viscosity. Rozzi et al. [5] experimentally compared smooth and helically corrugated tubes in the laminar and transitional flow regimes in a shell and tube heat exchanger, and used the Power-Law model to define the rheological behaviour of two pseudoplastic fruit purees.

In engineering applications, mainly in the food industry, many processes use high viscosity fluids. In these cases, the flow regime tends to be laminar, typically associated with low heat transfer coefficients. Moreover, in many industry applications that use heat exchangers, energy costs account for a high percentage of the total operation and maintenance costs. In this regard, methods to enhance heat exchanger tubes are essential in many of such applications. These methods can be defined as either active or passive [6,7]. One of the key aspects is improving heat transfer performance for more efficient use of these devices, with it being important to analyse flow behaviour and heat transfer performance in heat exchangers.

Some studies have experimentally reported that curved tubes as a passive heat transfer technique are commonly used in many industrial applications, such as nuclear industries, heat recovery systems or food processes [8,9]. In this case, these devices promote secondary flow, which helps improve heat transfer performance in comparison to a straight smooth pipe. Mori and Nakayama [10] analysed the effect of curvature on heat transfer for fully developed turbulent flow in curved pipes. They reported a significant increase in heat transfer rate in comparison to a straight pipe, considering wall heat flux boundary condition. Other works [11] have carried out experimental studies to analyse heat transfer and pressure drop in helical and spiral coils using non-Newtonian fluids. In this regard, Rao [12] proposed correlations to predict turbulent Nusselt number and friction factor for viscous Power-Law fluids in helical coils. Mujawar and Roa [13] studied pressure drop for several pseudoplastic polymer solutions, obtaining a correlation to calculate friction factor as a function of the curvature ratio. Mashelkar and Devarajan [14] analysed laminar flow for a Power-Law of non-Newtonian fluid, obtaining correlation for the friction factor using boundary layer approximation. Gratão et al. [15] experimentally studied laminar steady-state heat transfer in a pseudoplastic fluid food, through circular and concentric annular ducts. In addition, they measured the rheological properties in the ranges of $9.3-49.4^{\circ}$ Brix and $0.4-68.8^{\circ} \mathrm{C}$. In their study, empirical equations for Nusselt number were obtained, which were useful for manufacturers to design double-pipe and triple tube heat exchangers.

As a complementary activity to experimental activities and a prior step to the detailed designing of heat exchangers, computational fluid dynamic techniques (CFD) are a common tool for analysing heat exchanger performance. Few works have focused on studying non-Newtonian flow on pipe bends and coiled pipes [16,17] using numerical simulations. However, some studies [18] have carried out experimental and numerical investigationa of convective heat transfer in helically coiled tube heat exchangers, to study friction losses in a helical coil tube heat exchanger using laminar flow regime for a non-Newtonian fluid. In the cited study, the authors used water, glycerol-water mixtures, and diluted aqueous polymer solutions of Sodium Carboxy Methyl Cellulose and Sodium Alginate as non-Newtonian fluids. They developed innovative correlations for Nusselt number and friction factor for non-Newtonian fluids. Hence, Nusselt number was obtained as a function of one dimensionless number (M) [13], Prandtl number and coil curvature ratio, and the friction factor was obtained depending on the Dean number. Pawar and Sunnapwar [18] compared the correlations obtained for Nusselt number and friction factor with previous studies, and they obtained good agreement between experimental and numerical results. Hence, the average correlated Nusselt number was approximately $6 \%$ higher than the one proposed by Rajasekharan et al. [11]. Friction factor values obtained by Mashelkar and Devarajan [14] were higher than the obtained in the proposed correlation. Mirgolbabaei et al. [19] developed a numerical simulation of the mixed convection heat transfer from vertical helically coiled tubes in vertical helically coiled tube heat exchangers. They compared the 
numerical results with experimental data, finding that the heat transfer coefficient decreases as the tube diameter increases, considering the same coil pitch. Bandyopadhyay and Das [20] numerically analysed the flow of non-Newtonian liquid trough elbows, considering a laminar non-Newtonian pseudoplastic fluid. They concluded that the pressure drop for the $45^{\circ}$ elbow was higher than that of the $135^{\circ}$ elbow when analysing the influence of the curvature on the flow mixing process, depending of the type of elbow.

The aim of this work was to numerically simulate, with a non-Newtonian fluid in laminar regime, the heat transfer process in a tube with a curved elbow, similar to that used in double tube heat exchangers or in shell and tube heat exchangers with a U-tube bundle as the rear head. The rheological properties of the fluid were experimentally measured and the numerical model was previously validated with published correlations using water as heat transfer fluid (HTF).

\section{Numerical Simulations}

\subsection{Case Study and Mesh Generation}

A smooth curved tube heat exchanger made of stainless steel with an inner diameter of $18 \mathrm{~mm}$ and a wall thickness of $1 \mathrm{~mm}$ (see Figure 1) was used. The total length of the tube was approximately $1.6 \mathrm{~m}$, comprising two equal straight pipe sections of $0.75 \mathrm{~m}$ long and an elbow with a radius of $0.047 \mathrm{~m}$ and $0.148 \mathrm{~m}$ arc length. Two different HTFs were studied: liquid water and a commercially available fruit juice. First, the numerical scheme and the computational mesh were validated comparing the numerical results in turbulent regime obtained with water as the HTF, using widely recognised correlations available in the literature. The same mesh was then used to obtain the results of the non-Newtonian fruit juice in laminar regime. In both cases, to create a 3D mesh, the meshing process was performed with ANSYS Workbench v. 19.2 (ANSYS, Inc., Canonsburg, PA, USA) [21].

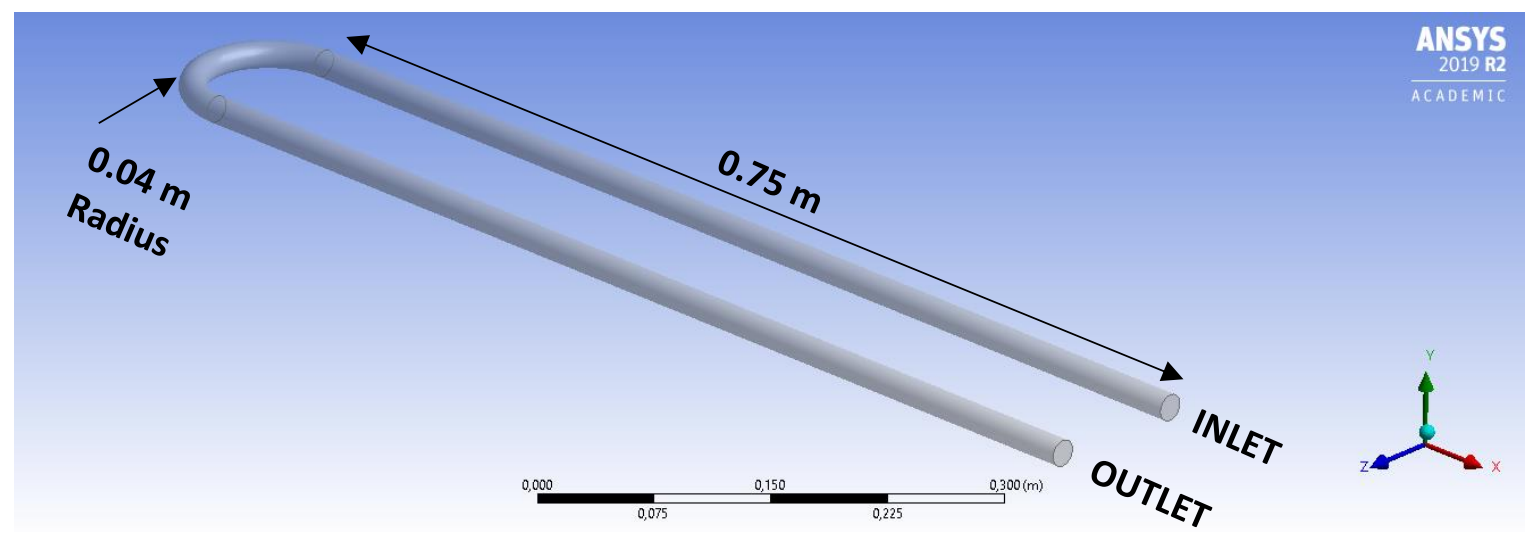

Figure 1. Case study.

Regarding the simulations using water as the HTF, an unstructured grid was defined with a refined mesh near the wall to ensure that the laminar viscous sub-layer was captured (see Figure 2). In this case, the Realizable $k-\varepsilon$ turbulence model with enhanced wall treatment was used to model the turbulence. The selected model is one the most commonly used to model the turbulence, considered consistent with the physics of turbulent flows, and characterised by its robustness and accuracy in heat transfer applications [21,22]. Several studies have used this model, especially in cases which analysed heat transfer in helically coiled tube heat exchangers [18] or studies related to analysing spirally corrugated tubes [23]. According to this model, the quality of the mesh near the wall was defined considering parameter $y^{+}$, which is defined as a non-dimensional distance to describe the fineness of the mesh for a specific flow condition [24]. Parameter $y^{+}$is defined as follows:

$$
y^{+}=\frac{y u_{\tau}}{v}
$$


where $y^{+}$is the dimensionless distance to the wall, $y$ is the distance to the wall, $u_{\tau}$ is the friction velocity and $v$ is the kinematic viscosity.

A grid independence analysis was carried out to examine the influence of the mesh size for the turbulent numerical simulations using water. Three unstructured grids with a refined mesh near the wall were used for the numerical simulations, representing a total of 402,000 (Grid 1), 510,000 (Grid 2) and 703,000 (Grid 3) tetrahedral cells. In total, 14 layers were defined at each grid and the first layer thickness yielded values of $0.06,0.01$ and $0.007 \mathrm{~mm}$ at Grids $1-3$, respectively.

Regarding the simulations using fruit juice as the HTF, the grid used was the one selected in the previous simulations carried out under turbulent regime.

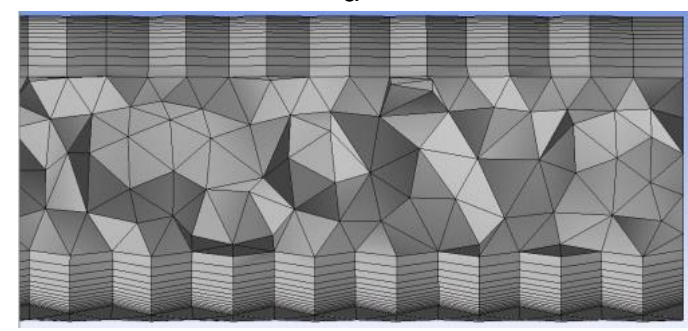

b
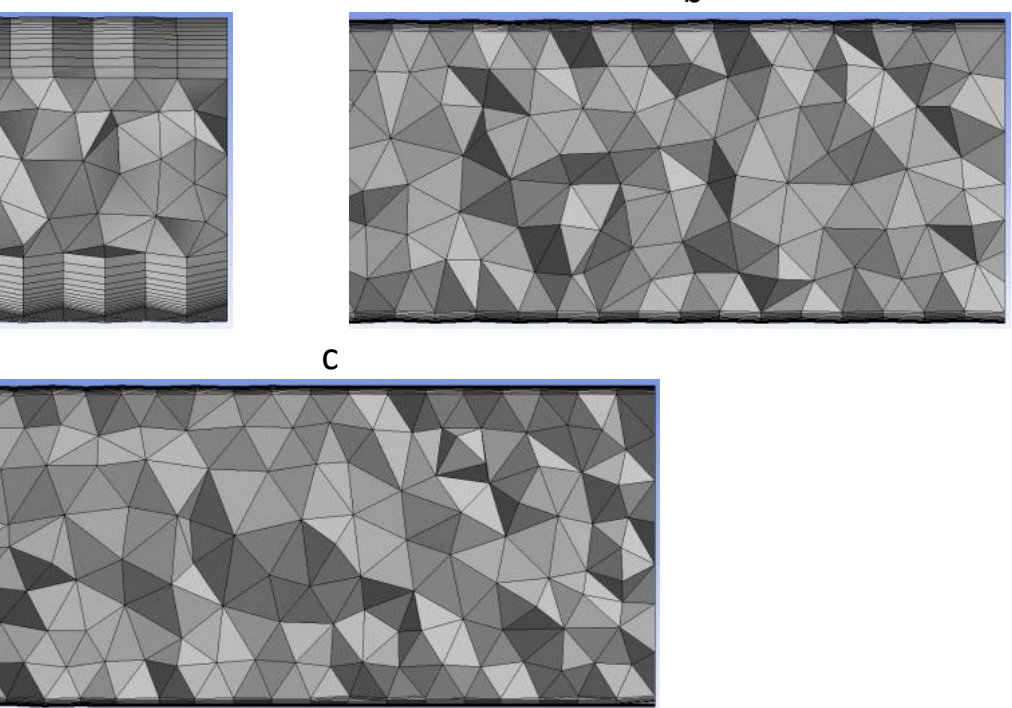

Figure 2. Mesh section for the turbulent numerical simulation using water of: Grid 1 (a); Grid 2 (b); and Grid 3 (c).

\subsection{Governing Equations}

In both simulations, under laminar and turbulent regime, the continuity equation (Equation (2)) was formulated as follows:

$$
\frac{\partial\left(\rho u_{i}\right)}{\partial x_{i}}=0
$$

For the laminar simulation, the momentum (Equation (3)) and energy (Equation (4)) equations were given as follows:

$$
\begin{gathered}
\frac{\partial}{\partial t}\left(\rho u_{i}\right)+\frac{\partial}{\partial x_{j}}\left(\rho u_{i} u_{j}\right)=-\frac{\partial p}{\partial x_{i}}+\frac{\partial}{\partial x_{j}}\left[\mu\left(\frac{\partial u_{i}}{\partial x_{j}}+\frac{\partial u_{j}}{\partial x_{i}}\right)\right] \\
\frac{\partial}{\partial t}(\rho T)+\frac{\partial}{\partial x_{i}}\left(\rho u_{i} T\right)=\frac{\partial}{\partial x_{j}}\left[\frac{\lambda}{c_{p}}\left(\frac{\partial T}{\partial x_{j}}\right)\right]
\end{gathered}
$$

With regard to the turbulent simulations, the equations were expressed in a Reynolds averaged Navier-Stokes (RANS) manner [23,25], with the momentum (Equation (5)) and heat transport (Equation (6)) equations defined as follows.

$$
\frac{\partial}{\partial t}\left(\rho u_{i}\right)+\frac{\partial}{\partial x_{j}}\left(\rho u_{i} u_{j}\right)=-\frac{\partial p}{\partial x_{i}}+\frac{\partial}{\partial x_{j}}\left[\mu\left(\frac{\partial u_{i}}{\partial x_{j}}+\frac{\partial u_{j}}{\partial x_{i}}-\frac{2}{3} \delta_{i j} \frac{\partial u_{k}}{\partial x_{k}}\right)\right]+\frac{\partial}{\partial x_{j}}\left(-\rho \overline{u_{i}^{\prime} u_{j}^{\prime}}\right)
$$




$$
\frac{\partial}{\partial t}(\rho T)+\frac{\partial}{\partial x_{i}}\left[u_{i}(\rho E+p)\right]=\frac{\partial}{\partial x_{j}}\left[\left(\lambda+\frac{c_{p} \mu_{t}}{P r_{t}}\right) \frac{\partial T}{\partial x_{j}}+\mu_{e f f} u_{i}\left(\frac{\partial u_{i}}{\partial x_{j}}+\frac{\partial u_{j}}{\partial x_{i}}-\frac{2}{3} \delta_{i j} \frac{\partial u_{k}}{\partial x_{k}}\right)\right]
$$

In addition, for the turbulent simulation, the Realizable $k-\varepsilon$ model was used to model the turbulence [26], under which the modelled transport equations for $k$ and $\varepsilon$ were

$$
\frac{\partial}{\partial t}(\rho k)+\frac{\partial}{\partial x_{j}}\left(\rho k u_{j}\right)=\frac{\partial}{\partial x_{j}}\left[\left(\mu+\frac{\mu_{t}}{\sigma_{k}}\right) \frac{\partial k}{\partial x_{j}}\right]+G_{k}+G_{b}-\rho \varepsilon+S_{k}
$$

and

$$
\frac{\partial}{\partial t}(\rho \varepsilon)+\frac{\partial}{\partial x_{j}}\left(\rho \varepsilon u_{j}\right)=\frac{\partial}{\partial x_{j}}\left[\left(\mu+\frac{\mu_{t}}{\sigma_{\varepsilon}}\right) \frac{\partial \varepsilon}{\partial x_{j}}\right]+\rho C_{1} S_{\varepsilon}-\rho C_{2} \frac{\varepsilon^{2}}{k+\sqrt{v \varepsilon}}+C_{1 \varepsilon} \frac{\varepsilon}{k} C_{3 \varepsilon} G_{b}+S_{\varepsilon}
$$

According to Fluent [21], the coefficients can be defined as follows: $C_{1}=\max (0.43, \eta /(\eta+5))$, $\eta=S k / \varepsilon, S=\sqrt{2 S_{i j} S_{i j}}, S_{i j}=\frac{1}{2}\left(\frac{\partial u_{i}}{\partial x_{j}}+\frac{\partial u_{j}}{\partial x_{i}}\right)$ and $G_{k}=-\rho \overline{u_{i}^{\prime} u_{j}^{\prime}} \frac{\partial u_{j}}{\partial x_{i}}$. The default values of the model constants were defined $\left(C_{2}=1.9, C_{1 \varepsilon}=1.44, \sigma_{k}=1.0, \sigma_{\varepsilon}=1.2\right)$ and $G_{b}, C_{3 \varepsilon}, S_{k}$ and $S_{\varepsilon}$ were not considered because gravitational force was neglected.

\subsection{Boundary Conditions}

In all the simulations under turbulent and laminar regime (for water and fruit juice, respectively), a steady-state model with three-dimensional incompressible flow was used. Regarding the boundary conditions, in both cases, velocity inlet was defined at the inlet section, considering uniform axial velocity and temperature, while the outlet condition was gauge pressure $\left(P_{\text {outlet }}=0\right)$. For the turbulent simulations, at the inlet, the turbulent intensity $I=5 \%$ and hydraulic diameter $\left(D_{h}=18 \mathrm{~mm}\right)$ were defined. At the wall, no slip boundary condition $(u=v=w=0)$ and a constant heat flux conditions of $\dot{q}=20,000 \mathrm{~W} / \mathrm{m}^{2}$ were defined. In both cases, the working fluid had an inlet temperature of $30^{\circ} \mathrm{C}$.

In the turbulent simulations with water, the thermophysical properties were assumed to be constant and are summarised in Table 1. In the case of the fruit juice, the regime was laminar and its density, thermal conductivity and specific heat were also defined as constant (see Table 1).

Table 1. Water and fruit juice properties at the inlet.

\begin{tabular}{cccc}
\hline Fluid & Density $\left(\mathbf{k g} / \mathbf{m}^{3}\right)$ & Thermal Conductivity $(\mathrm{W} / \mathbf{m ~ K )}$ & Specific Heat (J/kg K) \\
\hline Water & 998.2 & 0.618 & 4175 \\
\hline Fruit juice & 1016.5 & 0.550 & 3910 \\
\hline
\end{tabular}

Regarding the commercially available fruit juice, rheological properties were measured using a Modular Compact Rheometer (MCR-302, Anton Paar, Ostfildern-Scharnhausen, Germany). All mechanical and electrical motor components are incorporated into one unit. The unit had a Peltier modular temperature device type C-PTD 200 linked to a counter-cooling by fluid circulator, which allowed controlling the temperature of the product to be analysed within a range of between -30 and $200^{\circ} \mathrm{C}$. The viscometer had a high rotor speed with a powerful drive motor, which allowed a wide range of shear rates to be used. The measuring system was based on concentric cylinder geometry. The remaining fluid properties, such as density $(\rho)$, thermal conductivity $(\lambda)$ and specific heat $\left(c_{p}\right)$ were known. Using the MCR system, the rheological behaviour of the fruit juice samples was measured at seven temperatures, ranging from 24 to $55^{\circ} \mathrm{C}$, considering a shear rate from 1 to $800 \mathrm{~s}^{-1}$. The error expected for the temperature measurements and viscosity is $0.2^{\circ} \mathrm{C}$ and $1.5 \%$, respectively.

The fluid behaviour of the fruit juice was modelled using the Power-Law model.

$$
\sigma=K(\gamma)^{n}
$$


where $\sigma$ is the shear stress exerted by the fluid, $K$ is the consistency index, $\gamma$ is the shear rate and $n$ is the flow behaviour index.

To analyse the effect of the temperature on the rheological model, the dependence of the consistency index was modelled using the Arrhenius equation, determining the activation energy (Ea)

$$
\eta=A e^{\left(E a / R_{u} T\right)}
$$

where $\eta$ is the apparent viscosity, $A$ is a constant, $E a$ is the activation energy, $R_{u}$ is the universal gas constant and $T$ is the absolute temperature.

\subsection{Numerical Procedure}

Software Fluent (v. 19.2) [21] was used to compute fluid flow and heat transfer. In both cases, a double-precision and pressure-based solver was used to carry out the simulations. The Semi-Implicit Method for Pressure Linked Equations (SIMPLE) algorithm was used to couple the velocity and pressure fields [25]. The least square cell based option was selected for the spatial discretisation of the gradient, and second order upwind for the solution of the governing equations. The convergence criterion for the continuity equation was normalised residual values of $10^{-5}$ and $10^{-6}$ for the remaining variables.

To analyse the flow behaviour along the computational domain, several planes were defined (Figure 3). Moreover, the computational domain was divided into three sections, one section at the straight inlet pipe (between Planes 2 and 8), one at the straight outlet pipe (between Planes 12 and 18) and another at the elbow (between Planes 8 and 12).

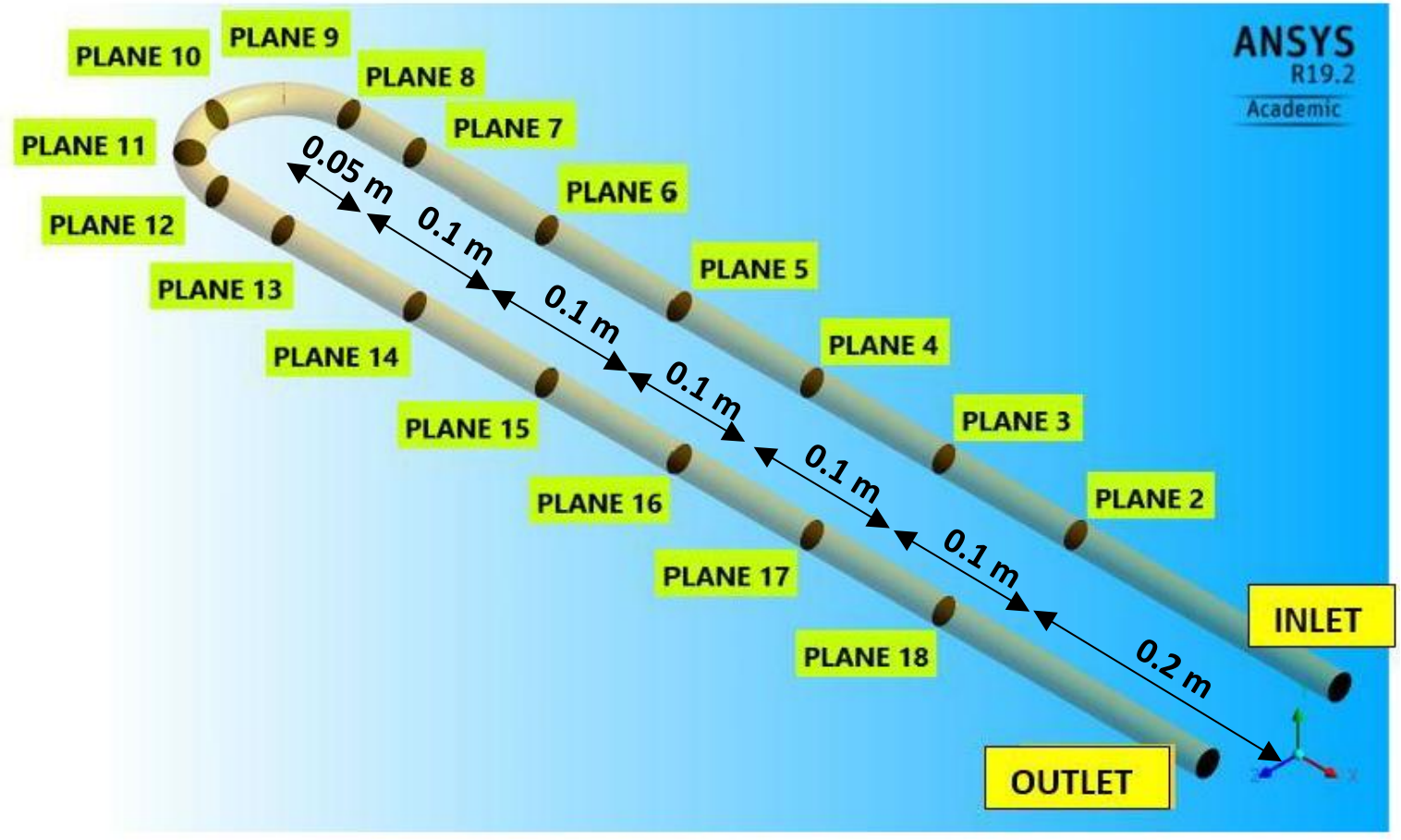

Figure 3. Plane locations along the computational domain.

At several specified locations, the local Nusselt number $\left(N u_{x}\right)$ and local heat transfer coefficient $\left(h_{x}\right)$ were computed as follows:

$$
N u_{x}=\frac{h_{x} D}{\lambda_{x}}
$$

and

$$
h_{x}=\frac{\dot{q}}{T_{w_{x}}-T_{f_{x}}}
$$


where $D$ is the inner tube diameter, $\lambda_{x}$ is the fluid thermal conductivity at temperature $T_{f_{x}}, \dot{q}$ is the heat flux in the tube, $T_{w_{x}}$ is the average inner wall temperature at position $x$ and $T_{f_{x}}$ is the average bulk fluid temperature at position $x$.

In addition, the pressure was determined at each plane location, so it was possible to determine the pressure drop $(\Delta p)$ along the curved pipe as well as the Fanning friction factor $\left(C_{f}\right)$ using the following equation [27]:

$$
C_{f}=\frac{\Delta p D}{2 \rho L u^{2}}
$$

where $C_{f}$ is the Fanning friction factor, $\Delta p$ is the total pressure difference, $\rho$ is the density, $L$ is the length of the pressure section and $u$ is the average fluid velocity.

With regard to the turbulent regime with water, to compare the results obtained from the simulations, the Fanning friction factor $\left(C_{f_{s}}\right)$ [27] and the Nusselt number $\left(N u_{s}\right)$ [28] for a straight smooth tube were computed as reference values using the following equations, respectively:

$$
C_{f_{s}}=\frac{0.3164 R e^{-0.25}}{4}
$$

and

$$
N u_{s}=\frac{\frac{f}{2} \operatorname{Re} \operatorname{Pr}}{1.07+12.7 \sqrt{\frac{f}{2}}\left(\operatorname{Pr}^{2 / 3}-1\right)}
$$

where the variable $f$ for Equation (15) is given by:

$$
f=\frac{1}{4(1.82 \log (R e)-1.64)^{2}}
$$

For the turbulent regime with water, Reynolds number (Re) of $45 \times 10^{3}$ was considered at the inlet, calculated as follows:

$$
R e=\frac{\rho u D}{\mu}
$$

where $\rho$ is the density, $u$ is the average fluid inlet velocity, $D$ is the inner diameter and $\mu$ is the dynamic viscosity.

Regarding the laminar simulations, the Fanning friction factor numerically obtained was compared to the theoretical Fanning factor obtained under laminar regime, defined as follows.

$$
C_{f_{s}}=\frac{16}{R e_{g}}
$$

In this case, the generalised Reynolds number $\left(R e_{g}=476\right)$, which is commonly implemented for non-Newtonian fluids for duct geometries with an uniform cross-section [29,30], was used at the inlet, and defined according to the following equation.

$$
\operatorname{Re}_{g}=\frac{\rho u^{2-n} D^{n}}{K^{\prime} 8^{n-1}}
$$

and

$$
K^{\prime}=K\left(\frac{3 n+1}{4 n}\right)^{n}
$$

where $\rho$ is the density, $u$ is the average fluid inlet velocity, $n$ is the flow behaviour index, $D$ is the inner diameter, $K^{\prime}$ is a constant and $K$ is the consistency index. 


\section{Results and Discussion}

\subsection{Rheological Measurements}

Figure 4 shows the rheological behaviour of the fruit juice at the different tested temperatures obtained in the laboratory, where the rheogram shows the non-linear Power-Law fit. The results for the fitting parameters are given in Table 2. In all cases, as expected, an increase in temperature resulted in a decrease in viscosity. Moreover, the flow behaviour index is lower than 1 , thus the fruit juice can be defined as a pseudoplastic fluid, with the viscosity decreasing as the shear rate increases. This trend is mainly noticeable at shear rates lower than $150 \mathrm{~s}^{-1}$.

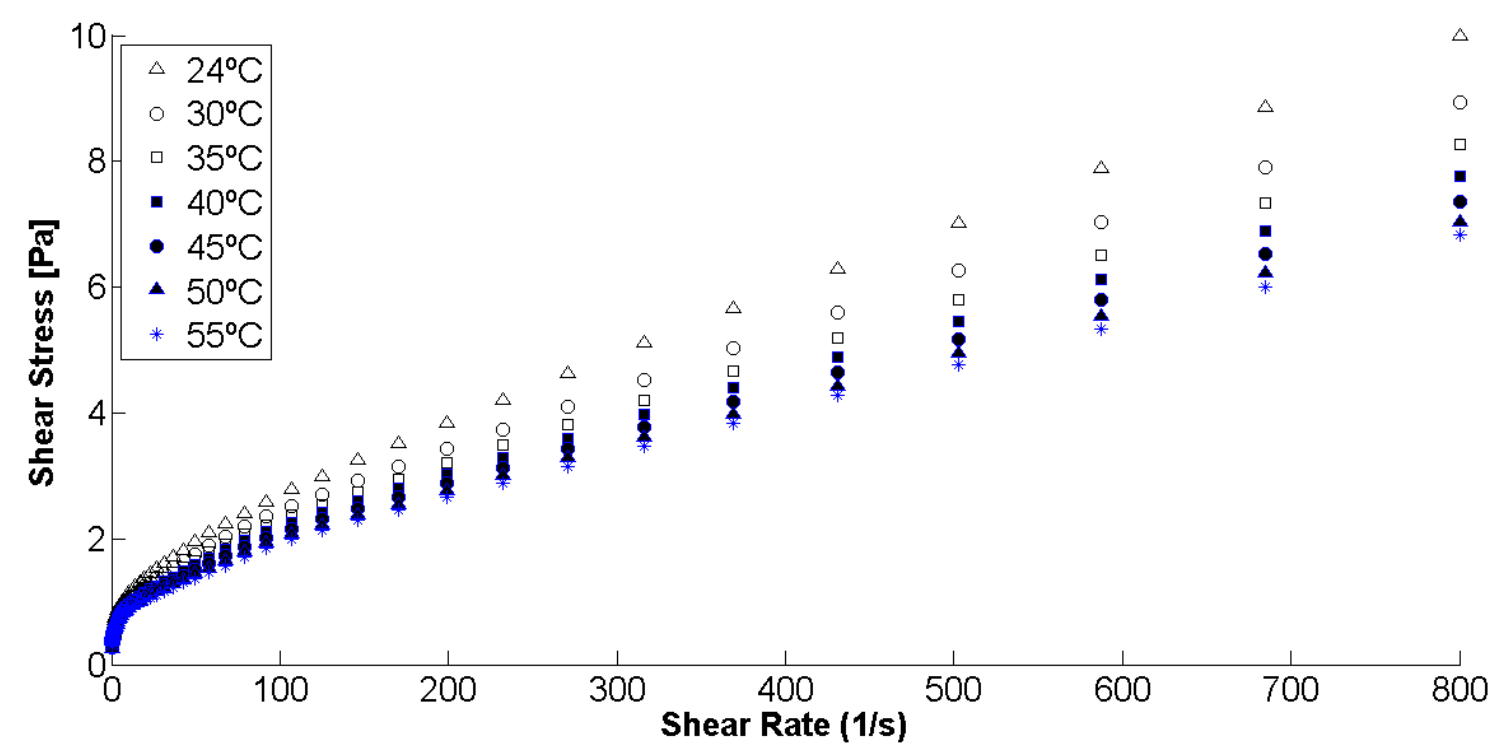

Figure 4. Shear rate vs. Shear stress curves of fruit juice at several temperatures.

Table 2. Power-Law equation fitting parameters of the fruit juice.

\begin{tabular}{cccc}
\hline$T^{\circ} \mathbf{C}$ & $K\left(\mathbf{P a} \cdot \mathbf{s}^{n}\right)$ & $\mathbf{n}$ & $r^{2}$ \\
\hline 24 & 0.247 & 0.539 & 0.987 \\
\hline 30 & 0.234 & 0.529 & 0.984 \\
\hline 35 & 0.237 & 0.514 & 0.982 \\
\hline 40 & 0.239 & 0.503 & 0.980 \\
\hline 45 & 0.238 & 0.495 & 0.978 \\
\hline 50 & 0.233 & 0.491 & 0.976 \\
\hline 55 & 0.222 & 0.493 & 0.975 \\
\hline
\end{tabular}

The effect of the temperature on the viscosity of the fruit juice at a specified shear rate was determined using the Arrhenius equation. Equation parameters and the apparent viscosity are shown in Tables 3 and 4.

Table 3. Apparent viscosity at $100 \mathrm{~s}^{-1}$ of fruit juice.

\begin{tabular}{cccccccc}
\hline $\boldsymbol{T}\left({ }^{\circ} \mathrm{C}\right)$ & $\mathbf{2 4}$ & $\mathbf{3 0}$ & $\mathbf{3 5}$ & $\mathbf{4 0}$ & $\mathbf{4 5}$ & $\mathbf{5 0}$ & $\mathbf{5 5}$ \\
\hline Apparent viscosity $(\eta, \mathrm{Pa} \cdot \mathrm{s})$ & 0.0296 & 0.0268 & 0.0254 & 0.0242 & 0.0232 & 0.0223 & 0.0215 \\
\hline
\end{tabular}


Table 4. Arrhenius equation fitting parameters.

\begin{tabular}{ccc}
\hline Activation Energy (kJ/mol) & A (Pa.s) & $\boldsymbol{r}^{2}$ \\
\hline 8.203 & 0.001047647 & 0.983 \\
\hline
\end{tabular}

\subsection{Model Validation with Liquid Water}

Regarding the turbulent numerical simulation using water, with a Reynolds number $(\operatorname{Re})=45 \times 10^{3}$ at the inlet, and considering the entire computational domain, the $y^{+}$distribution along the wall is shown in Figure 5. Hence, it is possible to compare these values according to the proposed grids. For the coarser grid (Grid 1), approximately $87 \%$ of data reached $y^{+}$values ranging from 3.5 to 4.5 , only representing $3.3 \%$ those data with $y^{+}$values ranged from 2.5 to 3.5 , slightly reducing the accuracy of the turbulence model used in the region close to the wall. It can be seen that the $y^{+}$obtained for Grids 2 and 3 showed the refined mesh generated using both grids. For Grid 2, approximately $99 \%$ of data showed $y^{+}$values ranging from 0.5 to 1.5 . For Grid 3, approximately $33 \%$ of data reached $y^{+}$values below 0.5 , and the remainder ranged from 0.5 to 1.5 .
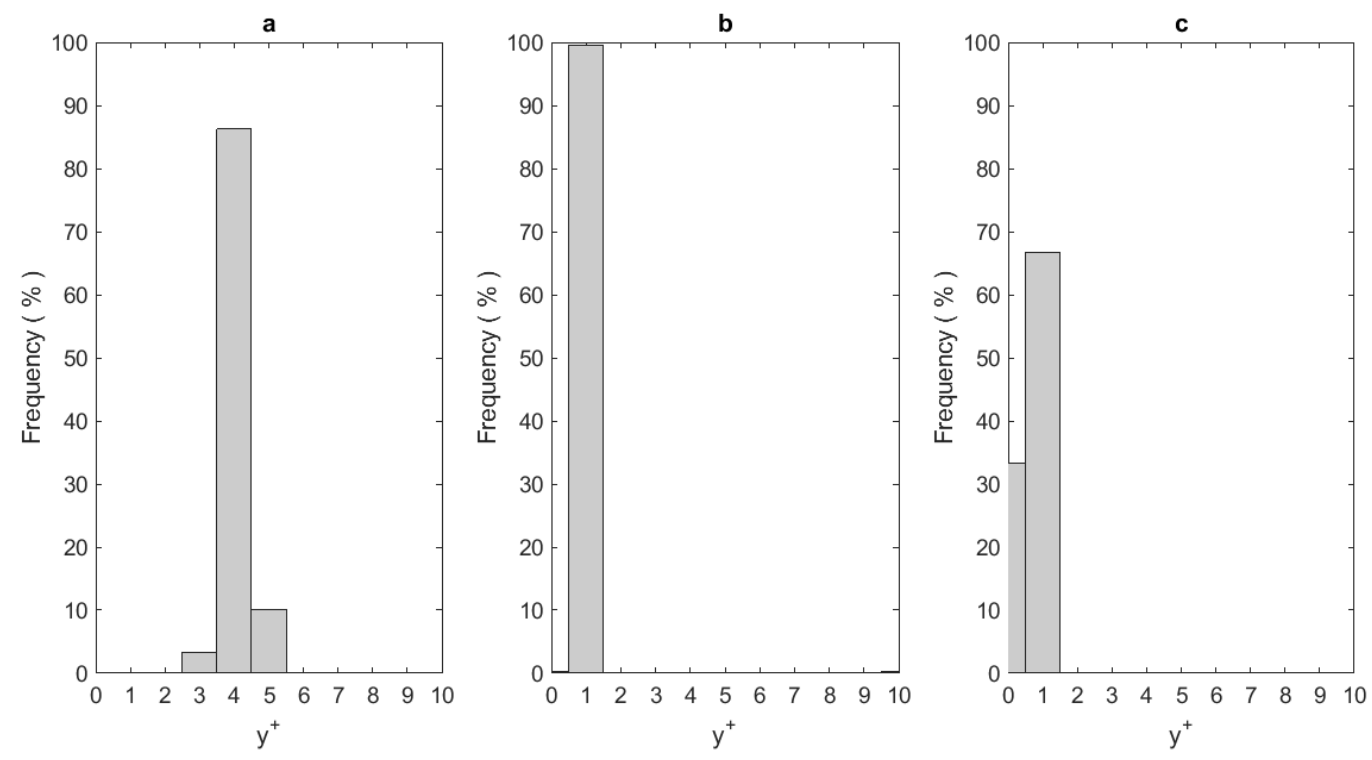

Figure 5. $y^{+}$distribution along the computational domain for the turbulent numerical simulation using water $\left(\operatorname{Re}=45 \times 10^{3}\right)$ with: Grid $1(\mathbf{a})$; Grid $2(\mathbf{b})$; and Grid $3(\mathbf{c})$.

To validate the proposed numerical simulations, we compared the numerical results using water in turbulent regime and those obtained with theoretical equations for a smooth tube. This comparison was restricted to the simulation results obtained in the straight inlet section of the tube. With this aim, the Fanning friction factor $\left(C_{f}\right)$ and Nusselt number $(\mathrm{Nu})$ along the straight inlet section (from Plane 2 to 8) of the computational domain were determined.

Regarding $C_{f}$, the most significant differences appear when comparing $C_{f}$ values at Grid 1 with respect to theoretical $C_{f}$ for a smooth tube (Table 5), where, at Grid 1, it reached a value approximately $10.5 \%$ lower than a smooth pipe. Similar $C_{f}$ values were obtained for Grids 2 and 3, where these discrepancies were greatly reduced when comparing both grids with the theoretical values, with a numerically obtained $C_{f}$ around $0.5 \%$ higher than the smooth pipe in both grids. With regard to the $\mathrm{Nu}$, the average value obtained at the planes located along the computational domain are shown in Table 5. Although no high differences were obtained for the three grids analysed, the $\mathrm{Nu}$ obtained at Grids 2 and 3 showed a value approximately $10.6 \%$ and $11 \%$ higher than the theoretical $\mathrm{Nu}$, respectively, with this difference being slightly higher $(15.6 \%)$ when using Grid 1. 
In the present study, the comparison of the numerical and theoretical $\mathrm{Nu}$ shows that the numerical results overestimate the theoretical data slightly but accurately predict the average $\mathrm{Nu}$. These results are in good agreement with those obtained by Córcoles-Tendero et al. [23], who carried out a numerical simulation of the heat transfer process in a simple smooth tube in turbulent regime using water. In that study, $\mathrm{Nu}$ numerically obtained was higher than the experimental $\mathrm{Nu}$, obtaining maximum discrepancies (for $\operatorname{Re}=40 \times 10^{3}$ ) ranging from $12 \%$ to $15 \%$, for Prandtl numbers of 2.9 and 4.3, respectively. Regarding the $C_{f}$, Córcoles-Tendero et al. [23] obtained maximum differences between experimental and numerical results around 5.5\%. Other researchers (e.g., [31]), reported that the comparison between the experimental and numerical overall heat transfer coefficients showed discrepancies within 5\%, in a study related to experimental and CFD estimation of the heat transfer in helically coiled heat exchangers.

Table 5. Theoretical and numerical Fanning friction factor and Nusselt number obtained at Grids 1-3 using water.

\begin{tabular}{ccccc}
\hline Variable & Grid 1 & Grid 2 & Grid 3 & Smooth Pipe \\
\hline Fanning factor $\left(C_{f}\right)$ & 0.0049 & 0.0055 & 0.0056 & 0.0054 \\
\hline Nusselt number $(\mathrm{Nu})$ & 318.4 & 304.8 & 306.1 & 275.6 \\
\hline
\end{tabular}

Figure 6 shows velocity magnitude distribution across centerline in three locations of the computational domain, at a distance of $0.15 \mathrm{~m}$ from the inlet, at $90^{\circ}$ of section bend (Plane 10) and at 0.3 $\mathrm{m}$ from the outlet (Plane 17). Velocity magnitude obtained with Grid 1 differs with the ones obtained with Grids 2 and 3, which are very similar. The highest differences are shown in the region close to the wall at the three locations, where Grid 1 overestimates velocity magnitude, which is approximately $15 \%$ higher than with the other grids. It indicates that Grid 1 also overestimates the hydrodynamic entry length in the tube. Hence, the velocity contour (Figure 7) using Grid 1 shows that the flow is fully developed at a distance of approximately $0.18 \mathrm{~m}$ from the inlet. Considering Grids 2 and 3, the flow development is reached earlier (at approximately of $0.11 \mathrm{~m}$ distance from the inlet).

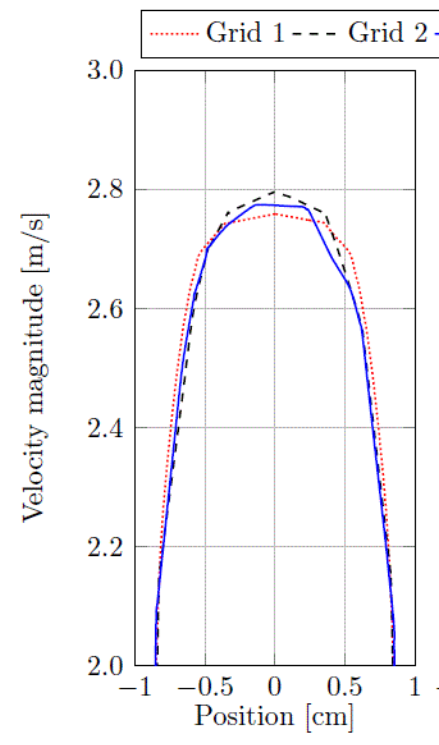

(a)

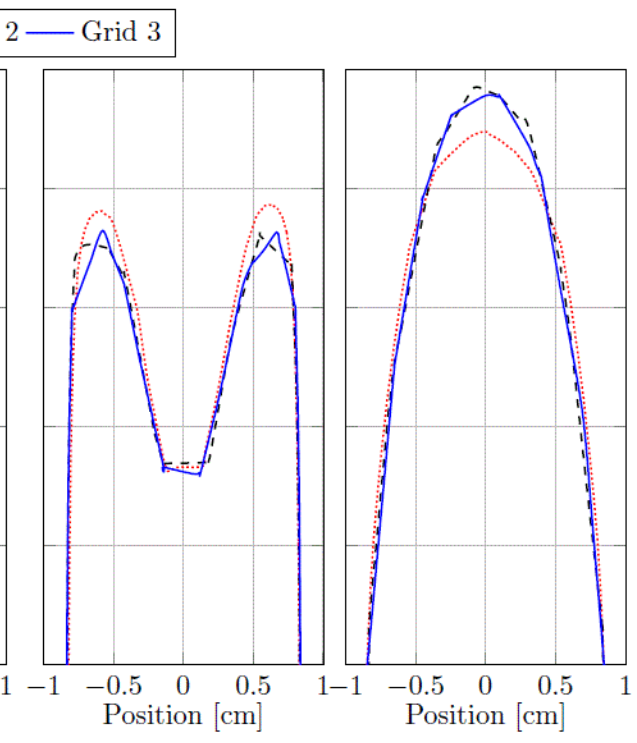

(b)

(c)

Figure 6. Velocity magnitude distribution across centerline for Grids 1-3 using water: at a distance of $0.15 \mathrm{~m}$ from the inlet (a); at $90^{\circ}$ of section bend (b); and at $0.3 \mathrm{~m}$ from the outlet (c). 


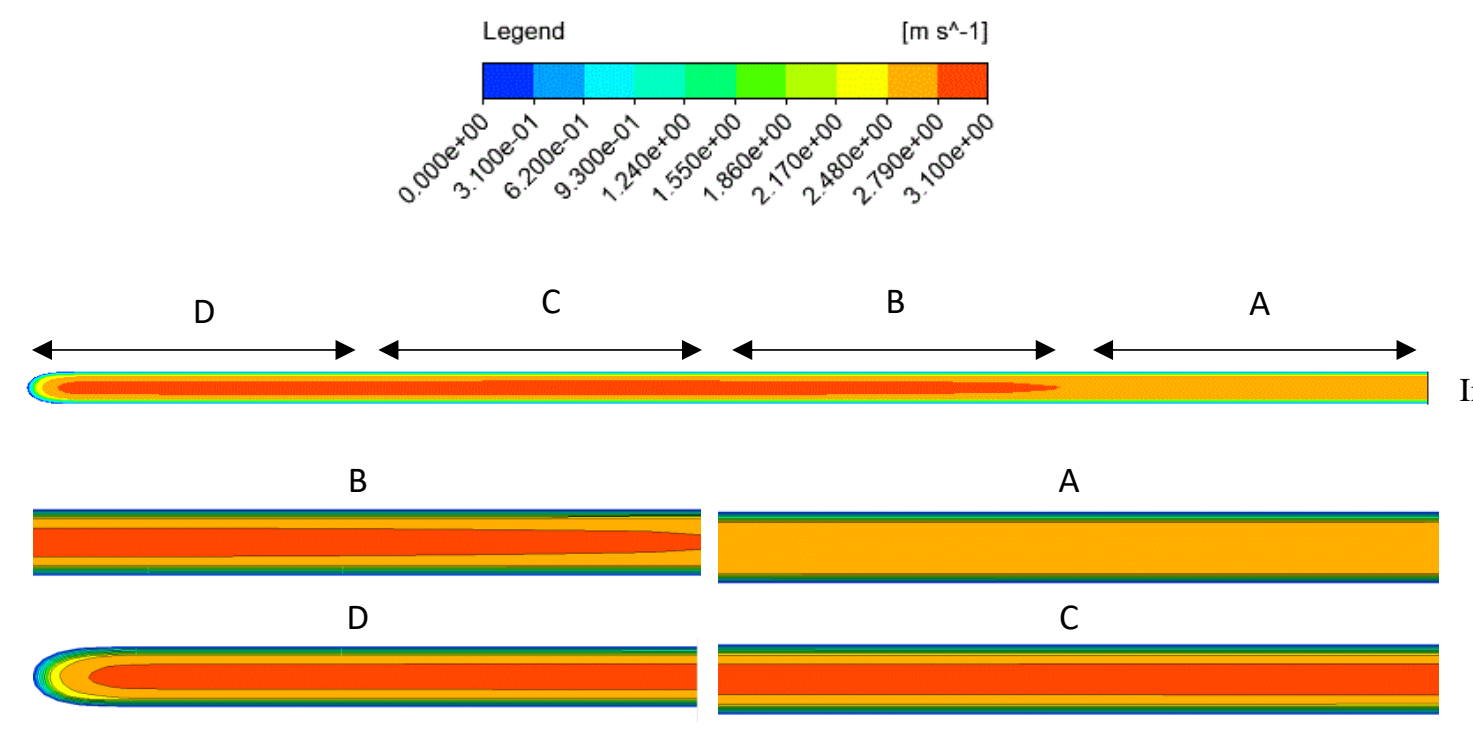

(a) Grid 1

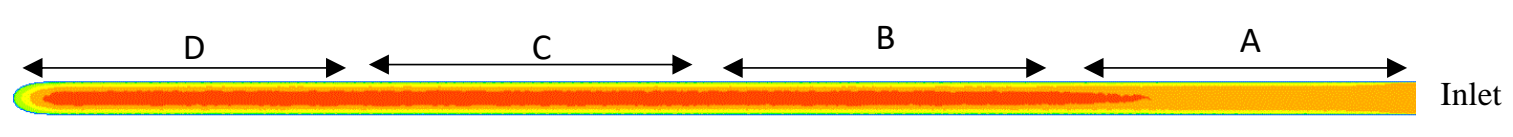

B

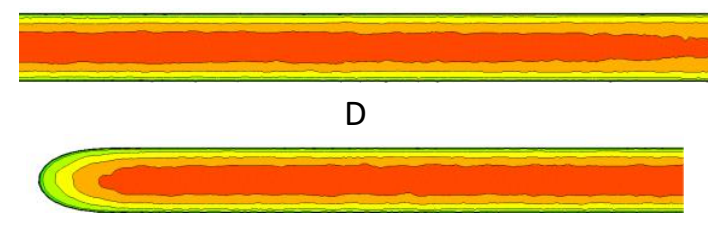

A

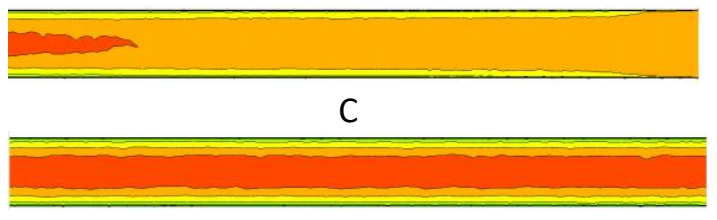

(b) Grid 2

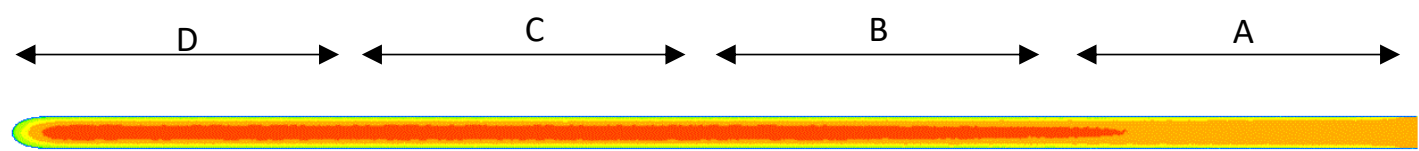

Inlet

B

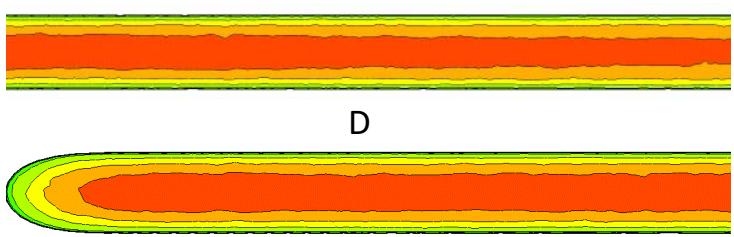

A

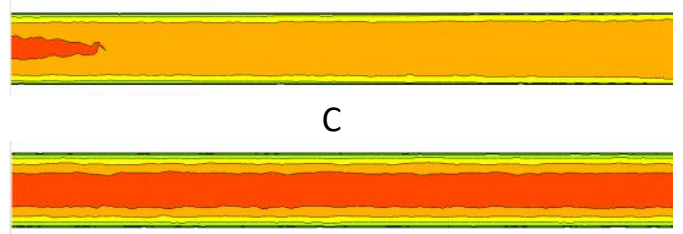

(c) Grid 3

Figure 7. Velocity magnitude contour distribution along the inlet section using water at: Grid 1 (a); Grid 2 (b); and Grid 3 (c).

According to the results obtained above, the lowest differences between numerical and theoretical results were shown using Grids 2 and 3. Moreover, in both cases, low $y^{+}$contributed to the accuracy of the wall treatment of the turbulence model. Grid 2 was considered the grid size with accurate results in turbulent regime, representing approximately $28 \%$ fewer cells than Grid 3. Grid 2 was selected because the $C_{f}$ and $\mathrm{Nu}$ numerically obtained showed low differences in comparison to the smooth pipe values. Accordingly, the selected grid was also used to simulate the case under laminar regime. 
Considering Grid 2, the pressure drop along the curved tube was calculated in the three analysed sections. The total pressure drop considering the entire computational domain was approximately $5560 \mathrm{~Pa}$, as a difference between total pressure at Planes 2 and 18. Analysing the three sections of the computational domain, it can be highlighted that the curved section (between Planes 8 and 12) represented approximately $19 \%$ of the total pressure drop in the pipe. The straight inlet (between Planes 2 and 8) and outlet (between Planes 12 and 18) sections represented $41 \%$ and $40 \%$, respectively, of the total pressure drop.

With regard to the temperature, Figure 8 shows the temperature contour distribution along the computational domain using the grid selected. The fluid temperature is more uniform along the inlet (Planes 2, 4 and 6) and outlet section (Planes 14, 16 and 18). For both sections, the average temperature at the centre of the pipe is lower than the region close to the wall. For the inlet section, the temperature at the wall reached maximum values of approximately $305.2 \mathrm{~K}$, slightly reducing at the centre (303.3 K). In the curved section (Planes 9-11), temperature variability is high, and smaller temperature differences can be seen between the temperature at the wall and the fluid temperature at the centre, related to the effect of the elbow on the flow behaviour, which promotes secondary and mixing flow. Figure 9 shows the average inner wall temperature and bulk fluid temperature across the plane locations. The wall temperature slightly increases in the upstream and downstream of the curved pipe, while it decreases in the curved pipe section, reaching the minimum values near the $90^{\circ}$ location (Planes 10 and 11). Regarding the bulk fluid temperature, it increases linearly along the computational domain. The temperature distribution help explain local $\mathrm{Nu}$ values across the plane locations (Figure 10), where the maximum values were reached at the curved section.
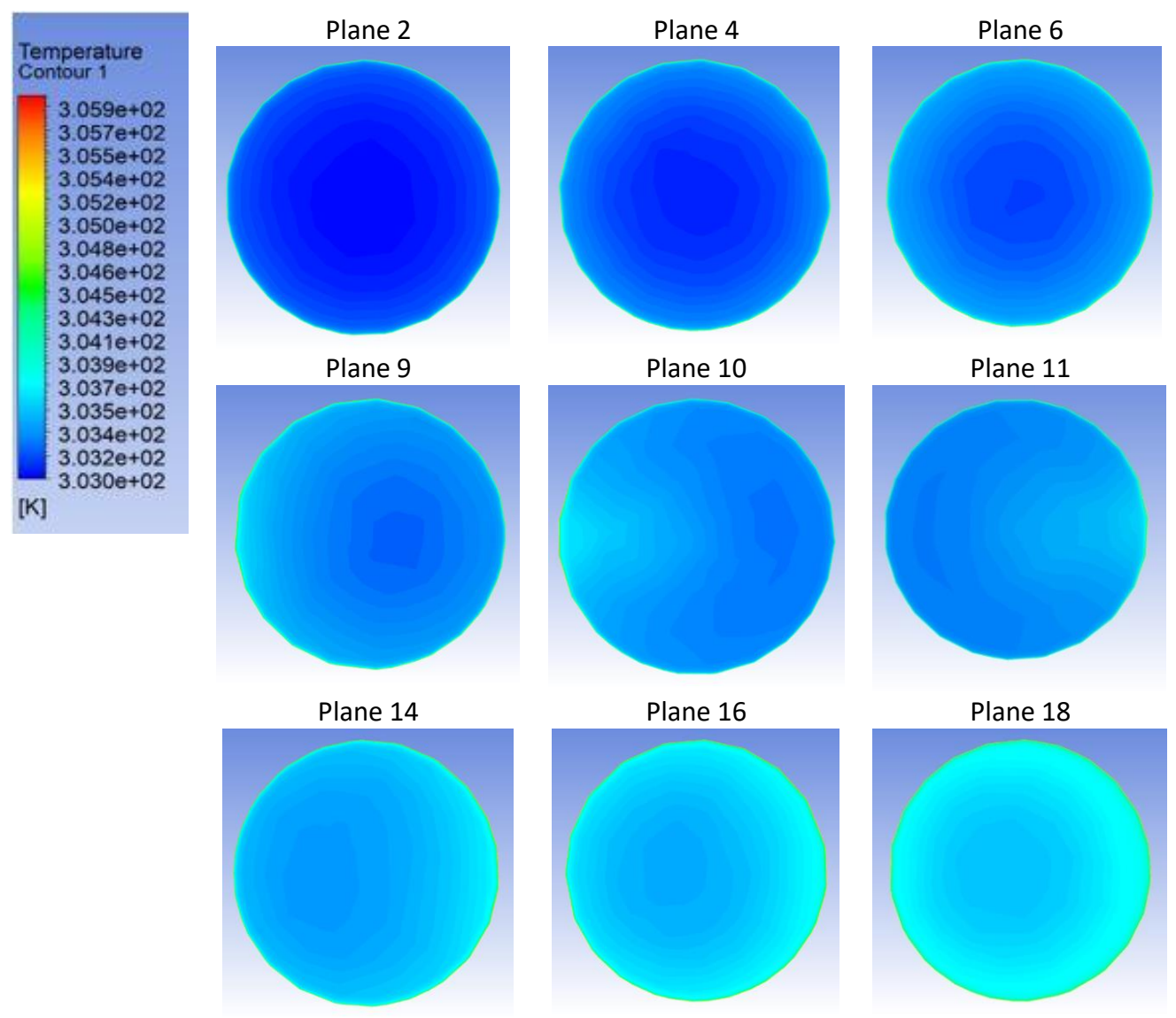

Figure 8. Temperature contour distribution at each plane location using water at Grid 2. 


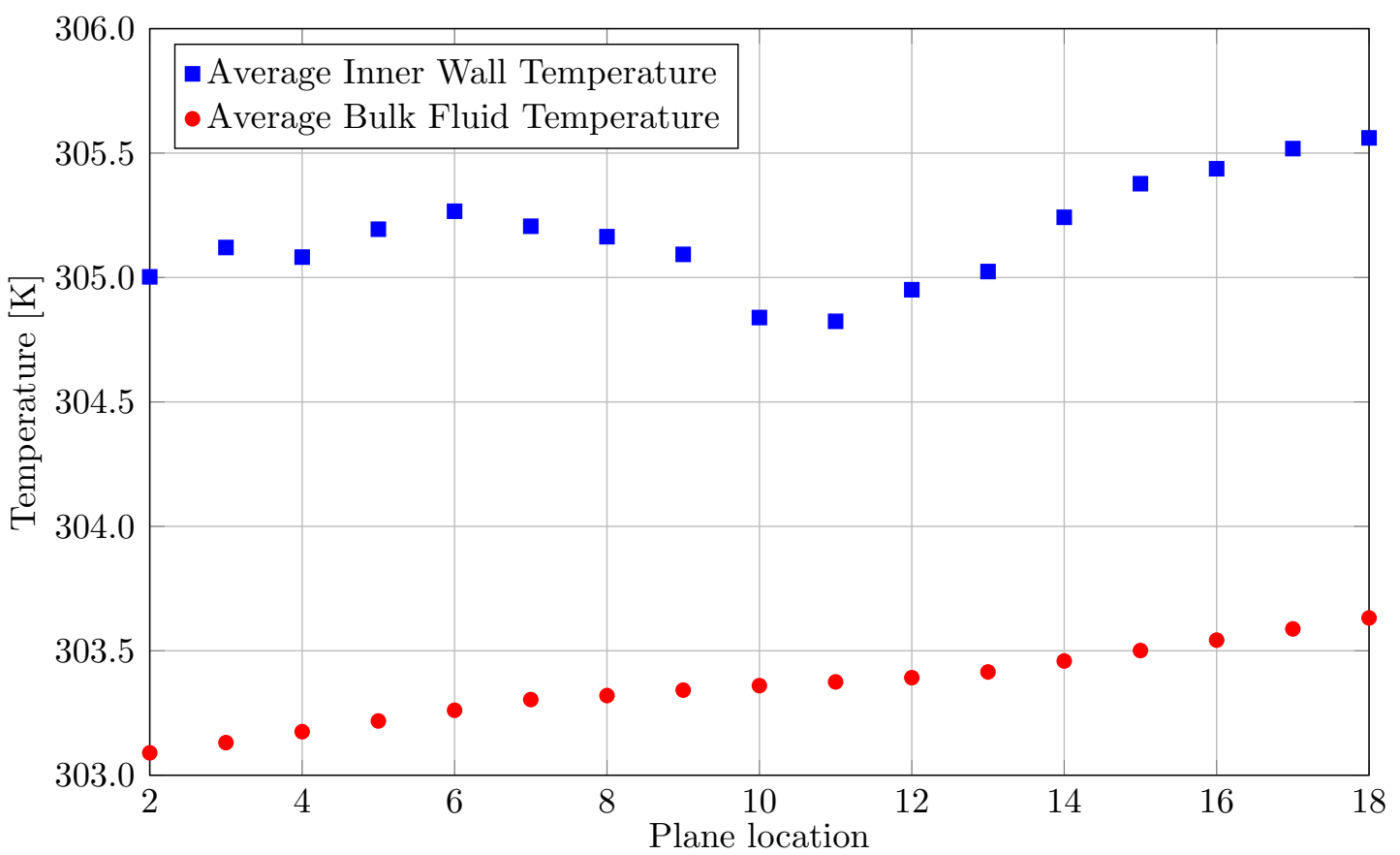

Figure 9. Wall and bulk fluid temperature at each plane location using water at Grid 2.

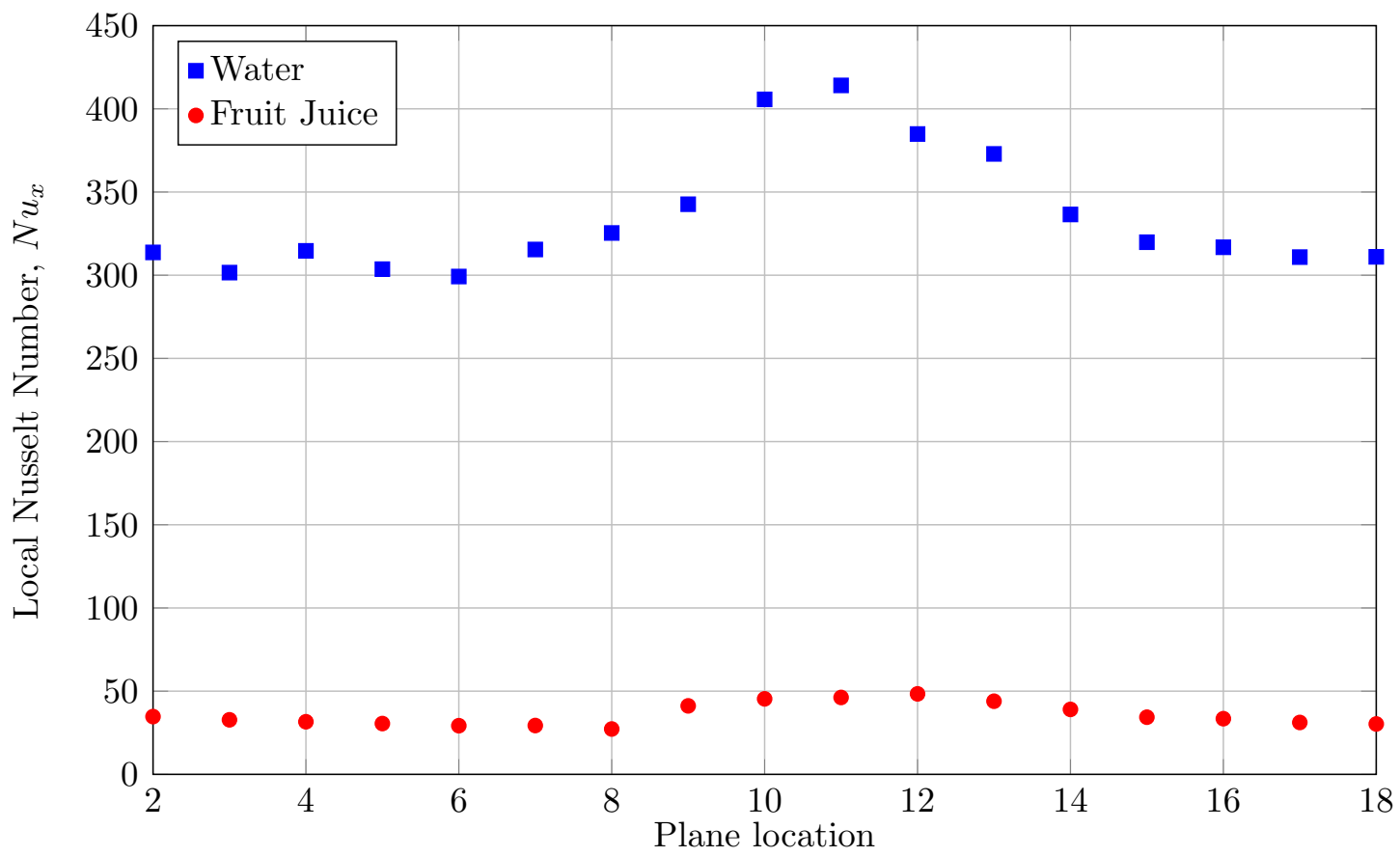

Figure 10. Local Nusselt number across the plane locations along the computational domain using fruit juice and water.

To complement the numerical results validation previously carried out for a straight smooth tube section, experimental and theoretical results for a curved pipe from other studies are included. Therefore, to validate the current numerical study in turbulent regime, $\mathrm{Nu}, C_{f}$ and loss coefficient $\left(K_{1}\right)$ were compared to theoretical values and experimental data proposed by other researchers focused on the curved section. Regarding $\mathrm{Nu}$, Chang [32] carried out an investigation of heat transfer characteristics of swirling flow in a $180^{\circ}$ circular section bend with uniform heat flux $\left(\dot{q}=5100 \mathrm{~W} / \mathrm{m}^{2}\right)$. 
In that study, a bend mean radius of $255 \mathrm{~mm}$ with an inner diameter of $54.5 \mathrm{~mm}$ was used. Although $\mathrm{Nu}$ values (151 and 181 for Re of $60 \times 10^{3}$ and $80 \times 10^{3}$, respectively) were slightly lower than the ones obtained in the current study, it can be highlighted that the maximum local Nu was reached along the near $90^{\circ}$ location, similar to the numerical $\mathrm{Nu}$ of the present study. Moreover, Chang [32] obtained a similar wall and bulk fluid temperature distribution as shown in Figure 9. In a previous study, Besserman and Tanrikut [33] analysed turbulent flow (Re ranging from $12.5 \times 10^{3}$ to $50 \times 10^{3}$ ) behaviour around a $180^{\circ}$ bend comparing with heat transfer measurements. In that study, experiments using a transient heat transfer technique with liquid crystal thermography were conducted, using a curved pipe with $29.7 \mathrm{~mm}$ radius and $25.1 \mathrm{~mm}$ inner diameter. Considering $\mathrm{Re}=50 \times 10^{3}$, the authors reported that the highest $\mathrm{Nu}$ (approximately 250) was reached near the $90^{\circ}$ location, similar to the results of the present study.

Some studies performed heat transfer analysis on the average heat transfer rate in curved and helical pipes [10,34,35], but most of them used different geometry shape to the proposed in the present study or used correlations only useful for a limited range of parameters. To validate the Nu numerically obtained for a curved pipe, the theoretical Schmidt's correlation [36] (Equation (21)) was used, where the ratio between $\mathrm{Nu}$ for a curved coil $\left(N u_{c}\right)$ and for the straight tube are computed $\left(N u_{s}\right)$. According to Kakaç et al. [37], although this correlation was proposed for a curved coil, it can also be used in $90^{\circ}$ bends for practical applications, applicable for Re ranging from $20 \times 10^{3}$ to $15 \times 10^{4}$ and ratio between radius of curvature (R) and tube inside radius (a) ranging from 5 to 84 . In the current study, the $N u_{c} / N u_{s}$ computed theoretically and numerically were 1.77 and 1.41 , respectively.

$$
\frac{N u_{c}}{N u_{s}}=1.0+3.6\left[1-\left(\frac{a}{R}\right)\right]\left(\frac{a}{R}\right)^{0.8}
$$

With regard to the $C_{f}$ and $K_{1}$, the numerical results have been compared to the theoretical equations proposed by other authors. According to Itō [38], the pressure drop in a bend for Re ranging from $20 \times 10^{3}$ to $40 \times 10^{4}$ is computed as follows.

$$
\Delta p_{b}=K_{1} \frac{\rho u^{2}}{2}
$$

for $\operatorname{Re}(R / a)^{-2}>91$

$$
K_{1}=0.00241 B \phi R e^{-0.17}(R / a)^{0.84}
$$

for $\phi=180^{\circ}$

$$
B=1+116(R / a)^{-4.52}
$$

Itō [38] proposed the following correlation (Equation (25)) to compute $C_{f_{c}}$ in a curved pipe in turbulent flow, which has a high degree of approximation according to other studies $[39,40]$.

$$
C_{f_{c}}=\frac{0.304 R e^{-0.25}+0.029(a / R)^{1 / 2}}{4}
$$

According to Equation (22), the numerical $K_{1}$ reached a value of 0.327 , obtained as a difference between total pressure at Planes 8 and 12 (approximately $1022 \mathrm{~Pa}$ ). Considering Equations (23) and (24), the theoretical $K_{1}(0.299)$ was approximately $8.5 \%$ lower than the numerical $K_{1}$. Comparing the $C_{f_{c}}$, the theoretical (Equation (25)) and numerical values obtained were 0.0084 and 0.0091 , respectively.

\subsection{Simulation Results with a Non-Newtonian Fruit Juice in Laminar Regime}

With regard to the non-Newtonian simulations, the results obtained for the $C_{f}$ and $\mathrm{Nu}$ were compared to the theoretical values obtained for a smooth tube in laminar regime. Figure 10 shows the local $\mathrm{Nu}$ corresponding to several plane locations along the computational domain. According to these 
values, the $\mathrm{Nu}$ presented similar values along the inlet and outlet section, increasing the values in the planes located in the curved section, which showed a similar tendency to the results obtained under water. It should be noted that the $\mathrm{Nu}$ values obtained did not correspond to a fully developed thermal flow in laminar regime. The numerically obtained $\mathrm{Nu}$ was compared to the theoretical correlation defined for a fluid with thermally profile in development [41] (Equation (26)). Considering a length of the straight tube $\left(L_{s}\right)$ of $0.75 \mathrm{~m}$, the Nu obtained was approximately 37.5 , slightly higher (31.4) than the average Nu numerically obtained in the current study. These discrepancies are related to the fact that the fruit juice properties are not constant along the computational domain, and this equation might not be useful for non-Newtonian fluids.

$$
N u_{s l}=4.36+\frac{\left[0.1156+\frac{0.08569}{P r^{0.4}}\right] G z}{\left[1+0.1158 G z^{0.6}\right]}
$$

where the Graetz number $(\mathrm{Gz})$ is given by:

$$
G z=\frac{D R e_{g} P r}{L_{s}}
$$

With regard to the $C_{f}$, as well as the $C_{f}$ obtained at the straight inlet section with the empirical Equation (18), the proposed correlation by Itō [38] for $C_{f_{c}}$ in a curved pipe in laminar flow (Equation (28)) has been used.

$$
C_{f_{c}}=\frac{16}{R e_{g}} \frac{21.5 D e}{(1.56+\log D e)^{5.73}}
$$

where the Dean number $(\mathrm{De})$ is given by:

$$
D e=\operatorname{Re}_{g}\left(\frac{a}{R}\right)^{1 / 2}
$$

According to these results, good agreement was found between the numerically obtained $C_{f}$ at the straight inlet section and the empirical Equation (18). The numerical $C_{f}$ obtained (0.0356) was approximately $5 \%$ higher than that theoretically computed (0.0336). Regarding the $C_{f_{c}}$, this parameter showed a value of 0.064 using the empirical Equation (28), approximately $3 \%$ higher than the $C_{f_{c}}$ numerically obtained (0.062).

Regarding the fruit juice simulation, the fluid velocity along the computational domain reached maximum values of $0.75 \mathrm{~m} / \mathrm{s}$ (Figures 11 and 12). The velocity behaviour is similar at the straight inlet and outlet section, with notable differences between the fluid velocity at the wall and the centre of the pipe. Slight variation in the fluid velocity can be seen in the planes located in the elbow. In this case, the fluid in the centre of the pipe tends to move to the outer side due to centrifugal forces, while the slow parts close to the wall are forced inward, to a zone with low pressure (Figure 13), making the flow move inward along the wall. Due to the curvature effect, fruit juice flows faster on the outer side (O) than on the inner side (I) curvature. In this case, this difference between inner and outer velocity is due to centrifugal force moving the fluid. 

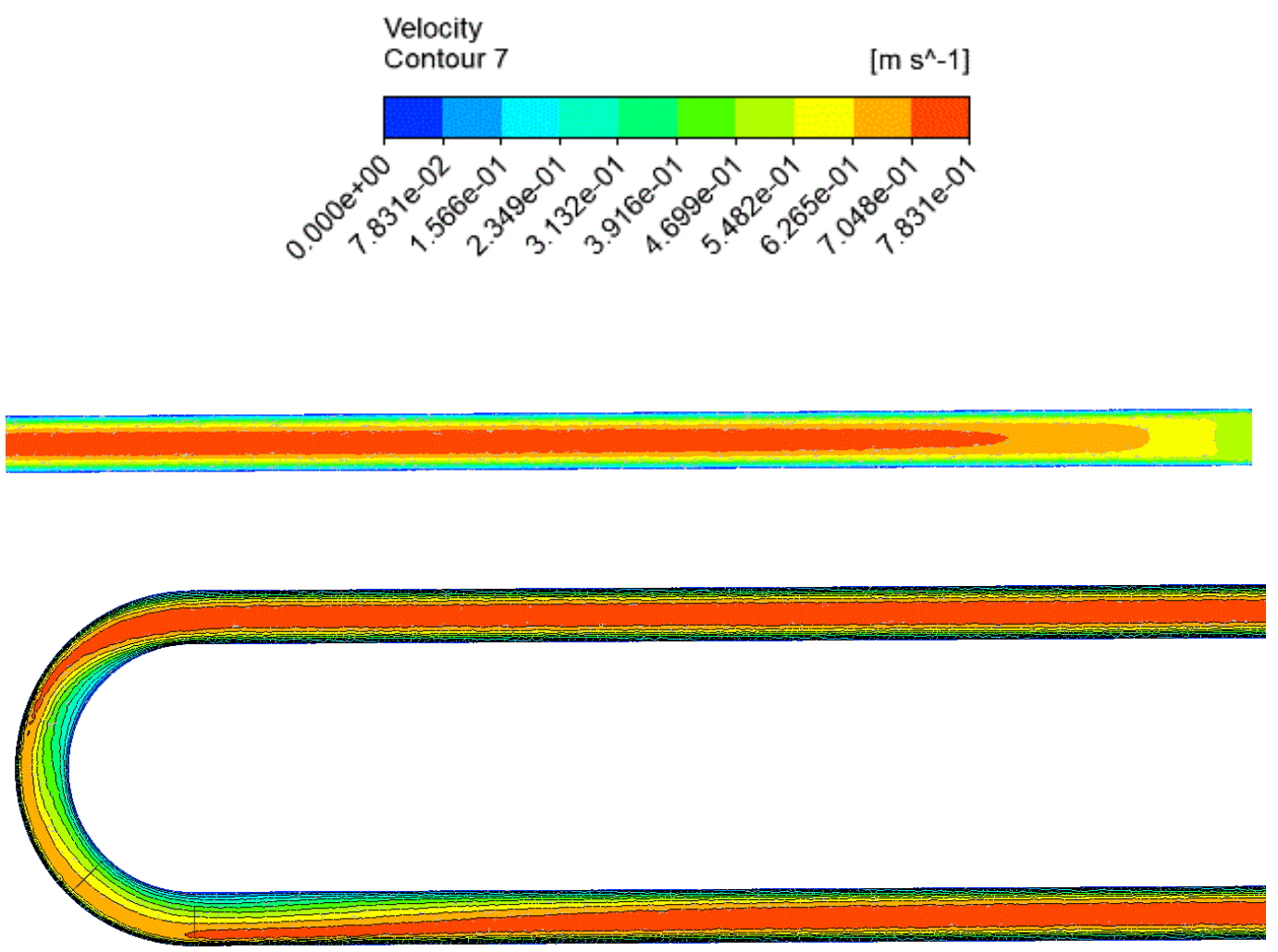

Inlet

Outlet

Figure 11. Velocity magnitude contour distribution along the inlet, curvature, and outlet sections using fruit juice.

Similarly to the turbulent regime, the values for the pressure drop along the computational domain were calculated in three sections of the curved tube. The total pressure drop considering the entire computational domain was found to be $64 \%$ lower than the case of water under turbulent regime. The straight inlet and outlet section represented $42 \%$ and $41 \%$, and the elbow section around $17 \%$.

With regard to the temperature distribution (Figures 14 and 15), significant differences between the temperature at the wall and the centre of the pipe can be observed in comparison to the simulations carried out with water. At the straight inlet and outlet section (Figure 14), the temperature at the centre of the pipe is more homogenous in comparison to the temperature distribution along the elbow, as can be also seen in Planes 9-11 (Figure 15). At the curvature, the maximum temperature reached a value close to $336 \mathrm{~K}$, in the region located at the inner side, reaching the minimum values $(303 \mathrm{~K})$ at the outer side. Regarding the inner wall temperature and bulk fluid temperature, Figure 16 shows a similar tendency to the results obtained under water, where the fluid temperature increases along the computational domain, while the wall temperature decreases in the curved pipe. Velocity changes indicated in Figure 12 can help explain temperature variability in the elbow, with moderately high temperatures being reached at the centre of the elbow, compared to the centre of the straight inlet and outlet section. 


\begin{tabular}{|c|}
\hline $\begin{array}{l}\text { Velocity } \\
\text { Contour } 1\end{array}$ \\
\hline $\begin{array}{l}7.594 \mathrm{e}-01 \\
-7.119 \mathrm{e}-01 \\
6.645 \mathrm{e}-01 \\
6.170 \mathrm{e}-01 \\
5.695 \mathrm{e}-01 \\
5.221 \mathrm{e}-01 \\
4.746 \mathrm{e}-01 \\
4.271 \mathrm{e}-01 \\
3.797 \mathrm{e}-01 \\
3.322 \mathrm{e}-01 \\
2.848 \mathrm{e}-01 \\
2.373 \mathrm{e}-01 \\
1.898 \mathrm{e}-01 \\
1.424 \mathrm{e}-01 \\
9.492 \mathrm{e}-02 \\
4.746 \mathrm{e}-02 \\
0.000 \mathrm{e}+00 \\
{\left[\mathrm{~m} \mathrm{~s}^{\wedge}-1\right]}\end{array}$ \\
\hline
\end{tabular}

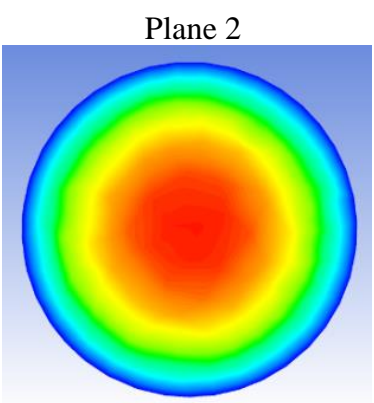

Plane 9

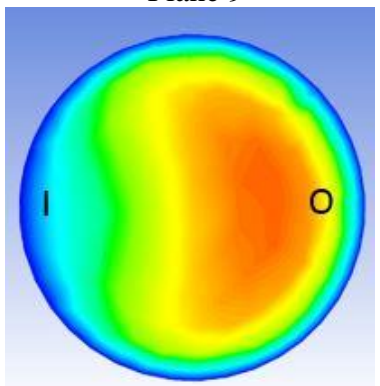

Plane 14

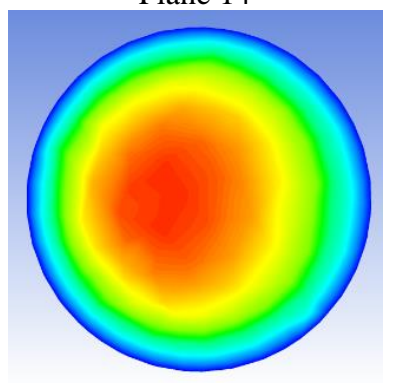

Plane 4

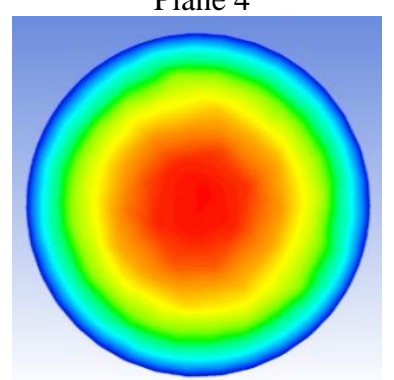

Plane 10

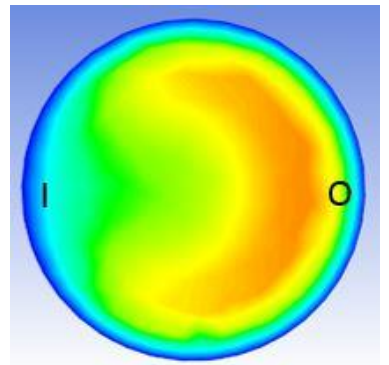

Plane 16

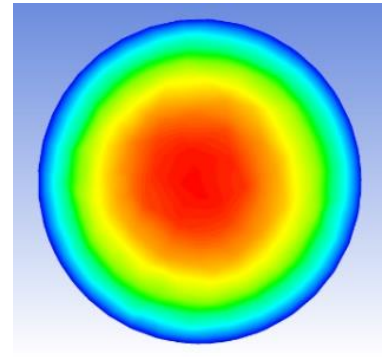

Plane 6

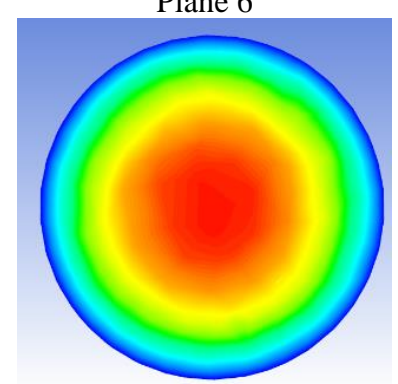

Plane 11

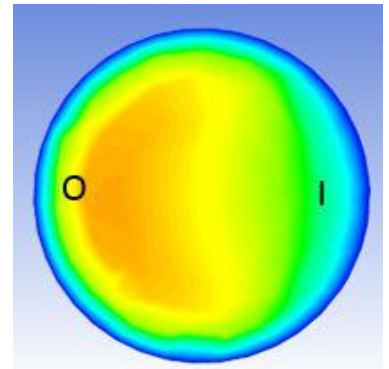

Plane 18

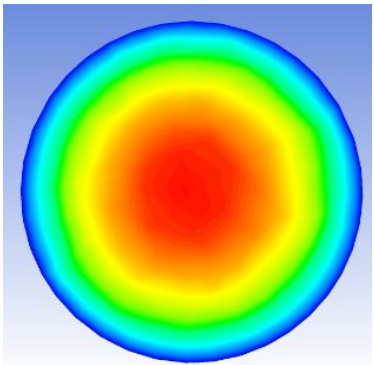

a

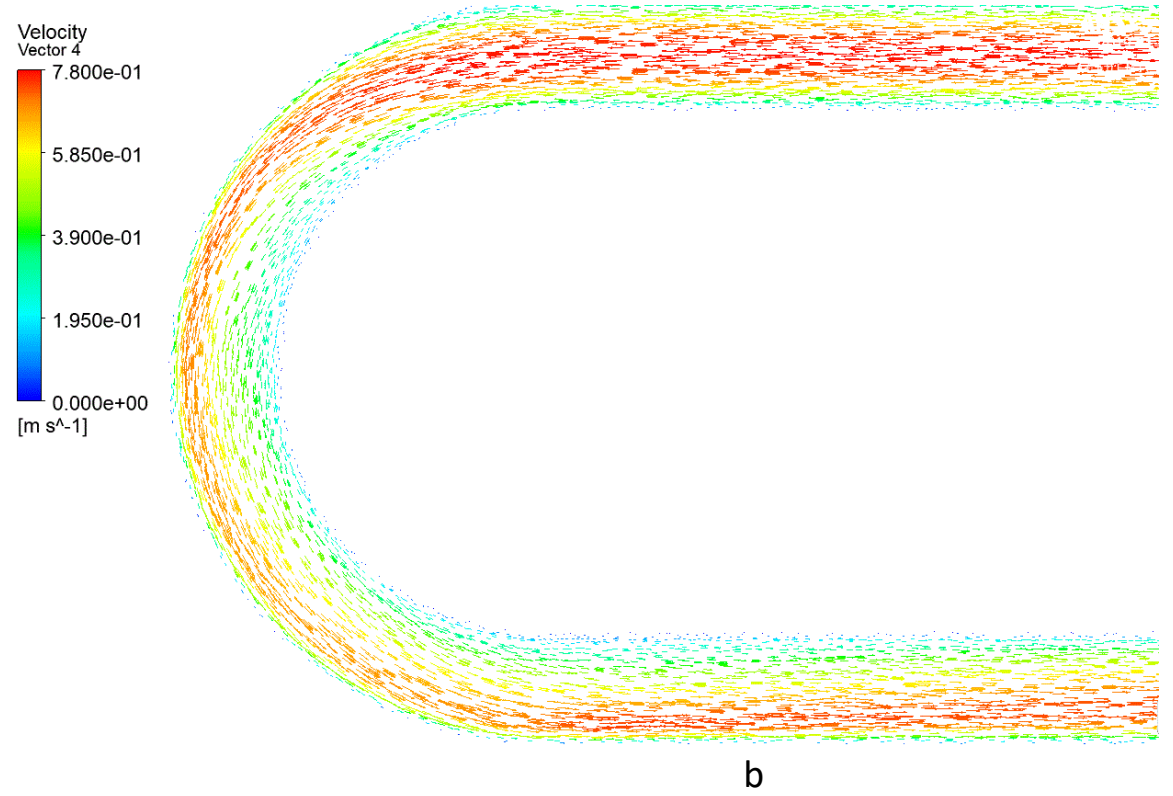

Figure 12. Velocity magnitude contour distribution across the plane locations (a) and velocity vectors along the curvature section (b) using fruit juice. 

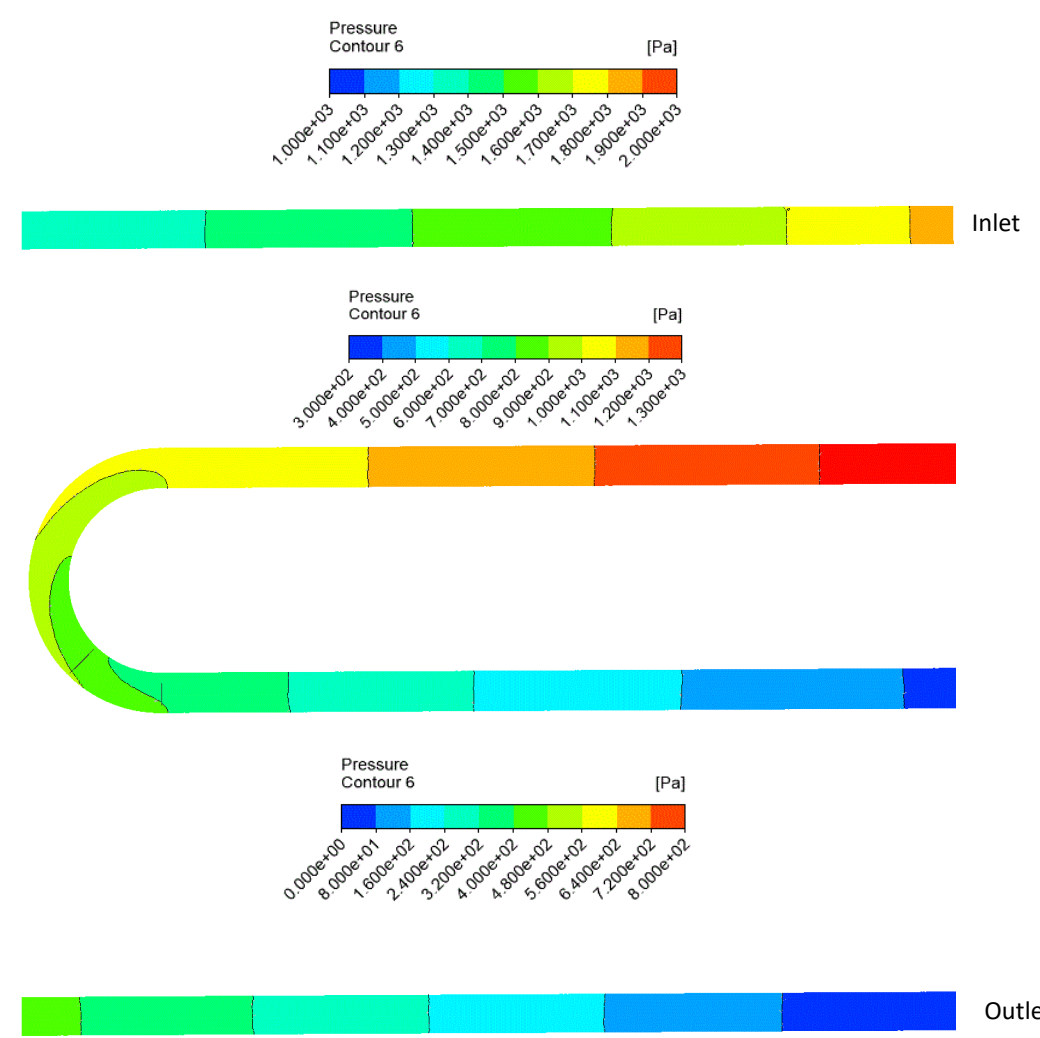

Outlet

Figure 13. Pressure contour distribution along the inlet, curvature and outlet sections using fruit juice.
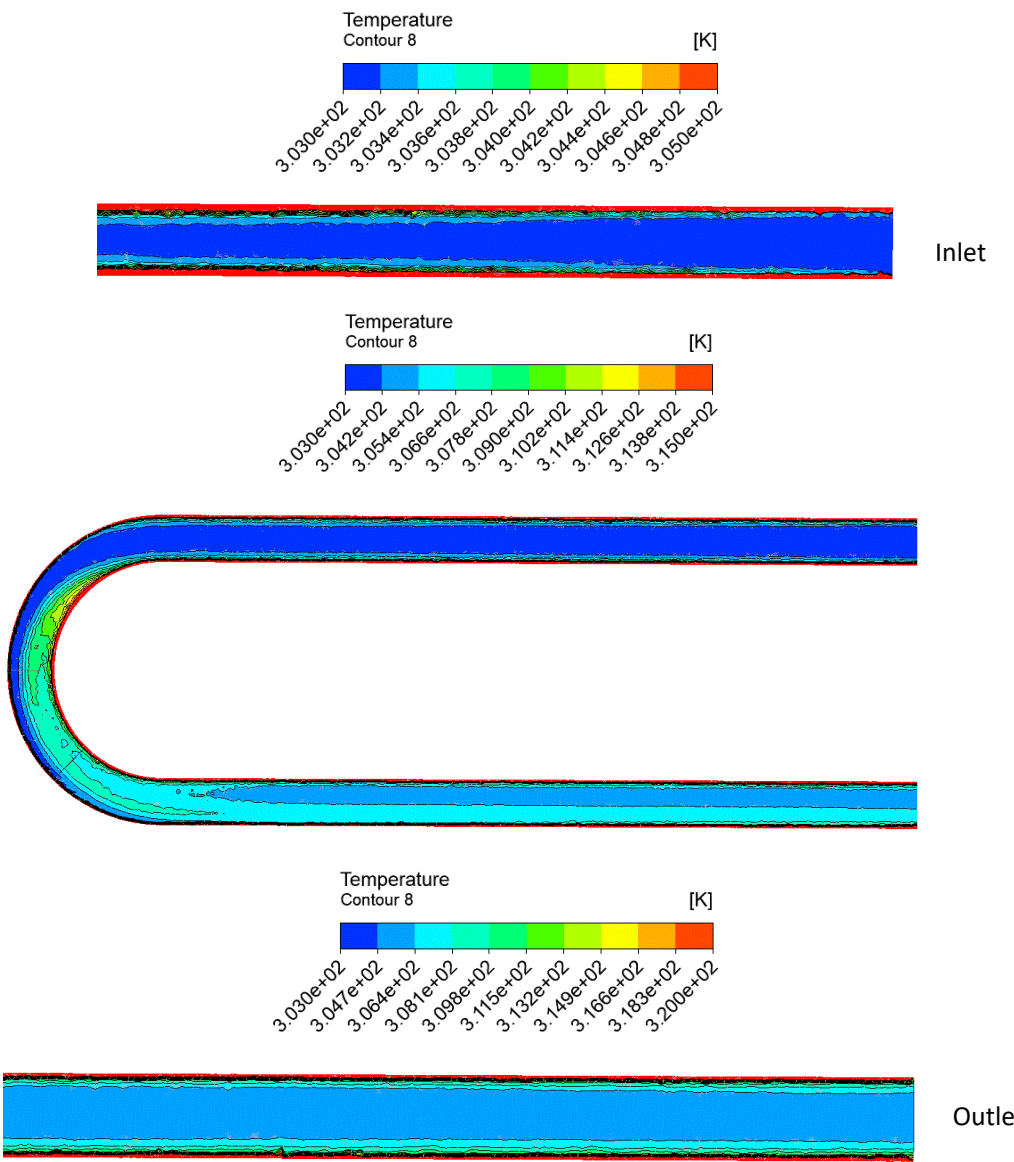

Outlet

Figure 14. Temperature contour distribution along the computational domain using fruit juice. 


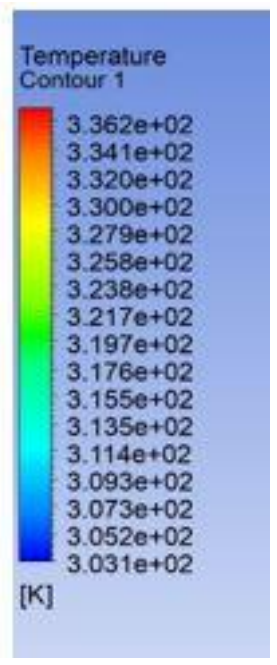

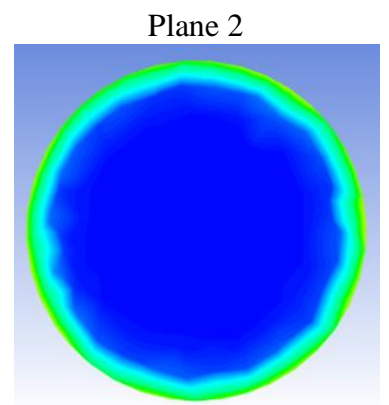

Plane 9

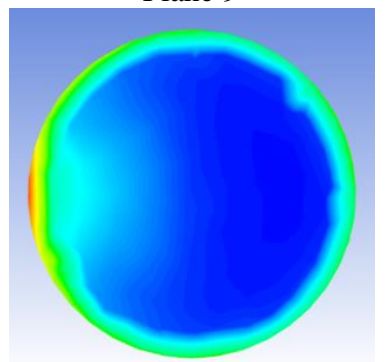

Plane 14

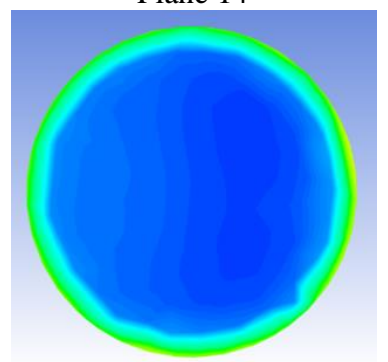

Plane 4

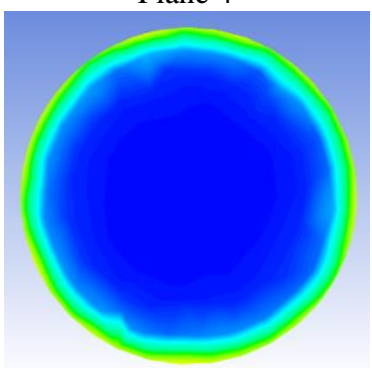

Plane 10

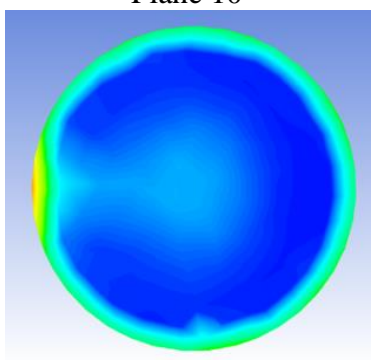

Plane 16

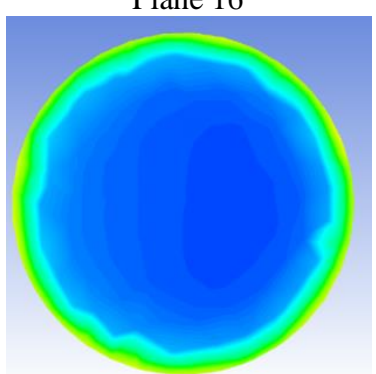

Plane 6

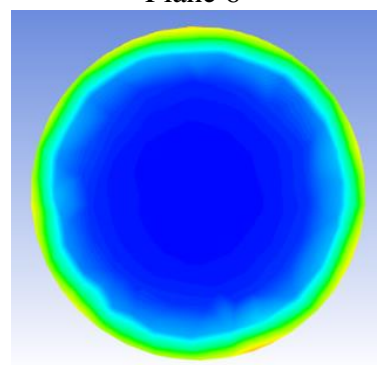

Plane 11

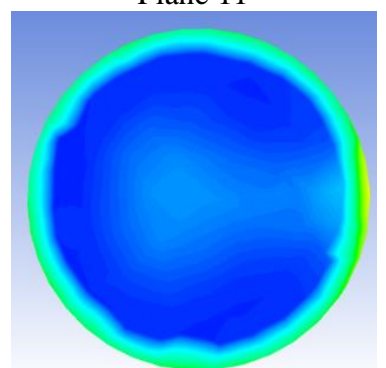

Plane 18

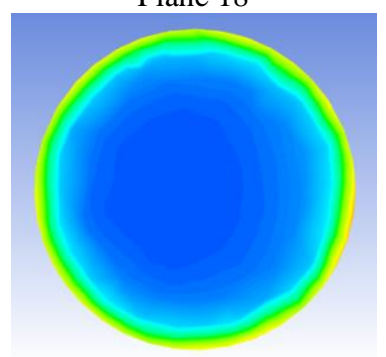

Figure 15. Temperature contour distribution at each plane location using fruit juice.

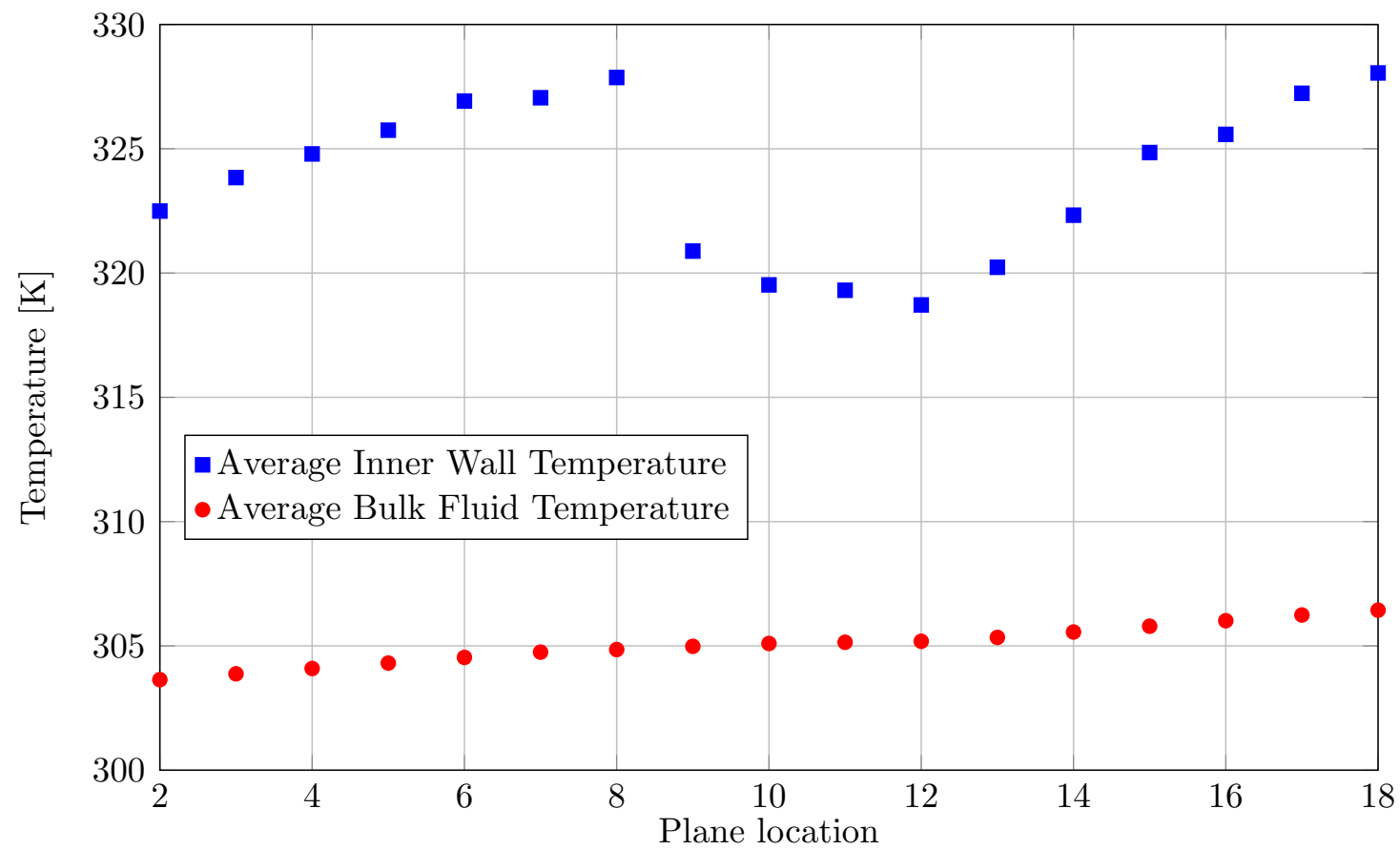

Figure 16. Wall and bulk fluid temperature at each plane location using fruit juice. 
Figures 17 and 18 show the strain rate and dynamic viscosity distribution along the straight inlet and the elbow section. The viscosity distribution for the straight outlet section was very similar to the inlet. The strain rate showed the highest values at the wall, reaching maximum values ranging from 300 to $800 \mathrm{~s}^{-1}$ (Figure 17). At the centre of the pipe, the strain rate decreases, reaching values between 0 to $50 \mathrm{~s}^{-1}$. This is related to the velocity variation between the fluid layers being lower at the centre of the pipe compared to the wall. The highest dynamic viscosity values were found at the centre of the pipe (between 0.05 and $0.09 \mathrm{~Pa} \cdot \mathrm{s}$ ), with the lowest values at the wall (0.0076 Pa.s) (Figure 18). This behaviour is explained by the pseudoplastic condition of the fruit juice, where viscosity increases as the shear rate decreases.

\begin{tabular}{|c|}
\hline $\begin{array}{l}\text { Strain Rate } \\
\text { Contour } 1\end{array}$ \\
\hline $\begin{array}{l}9.697 \mathrm{e}+02 \\
9.091 \mathrm{e}+02 \\
8.485 \mathrm{e}+02 \\
7.879 \mathrm{e}+02 \\
7.273 \mathrm{e}+02 \\
6.667 \mathrm{e}+02 \\
6.061 \mathrm{e}+02 \\
5.455 \mathrm{e}+02 \\
4.848 \mathrm{e}+02 \\
4.242 \mathrm{e}+02 \\
3.636 \mathrm{e}+02 \\
3.030 \mathrm{e}+02 \\
2.424 \mathrm{e}+02 \\
1.818 \mathrm{e}+02 \\
1.212 \mathrm{e}+02 \\
6.061 \mathrm{e}+01 \\
0.000 \mathrm{e}+00 \\
{\left[\mathrm{~s}^{\wedge}-1\right]}\end{array}$ \\
\hline
\end{tabular}

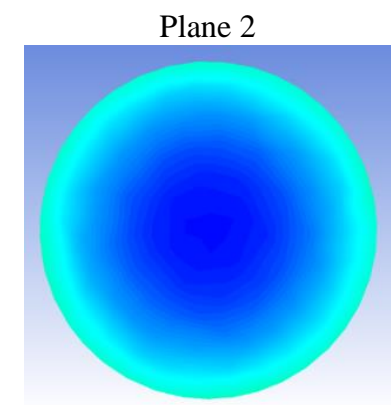

Plane 9

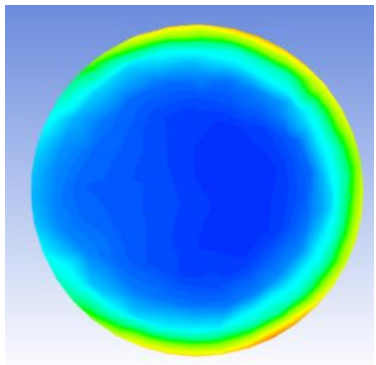

Plane 4

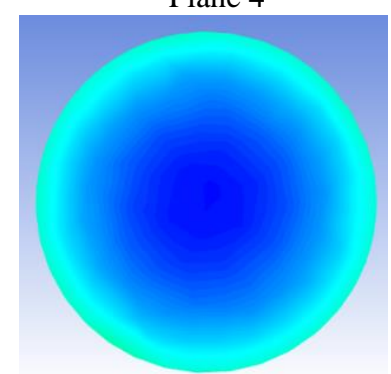

Plane 10

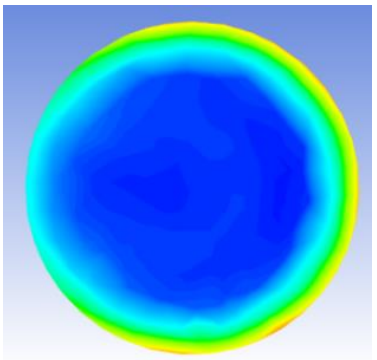

Plane 6

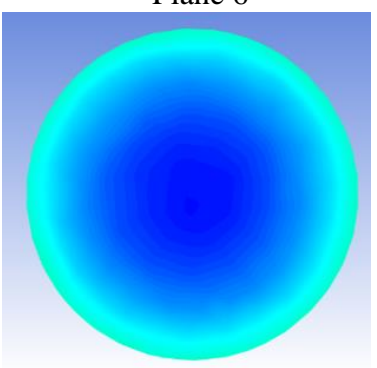

Plane 11

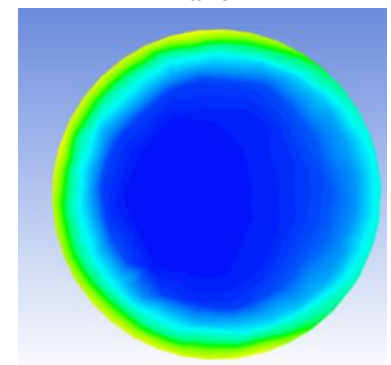

Figure 17. Strain rate at each plane location using fruit juice.
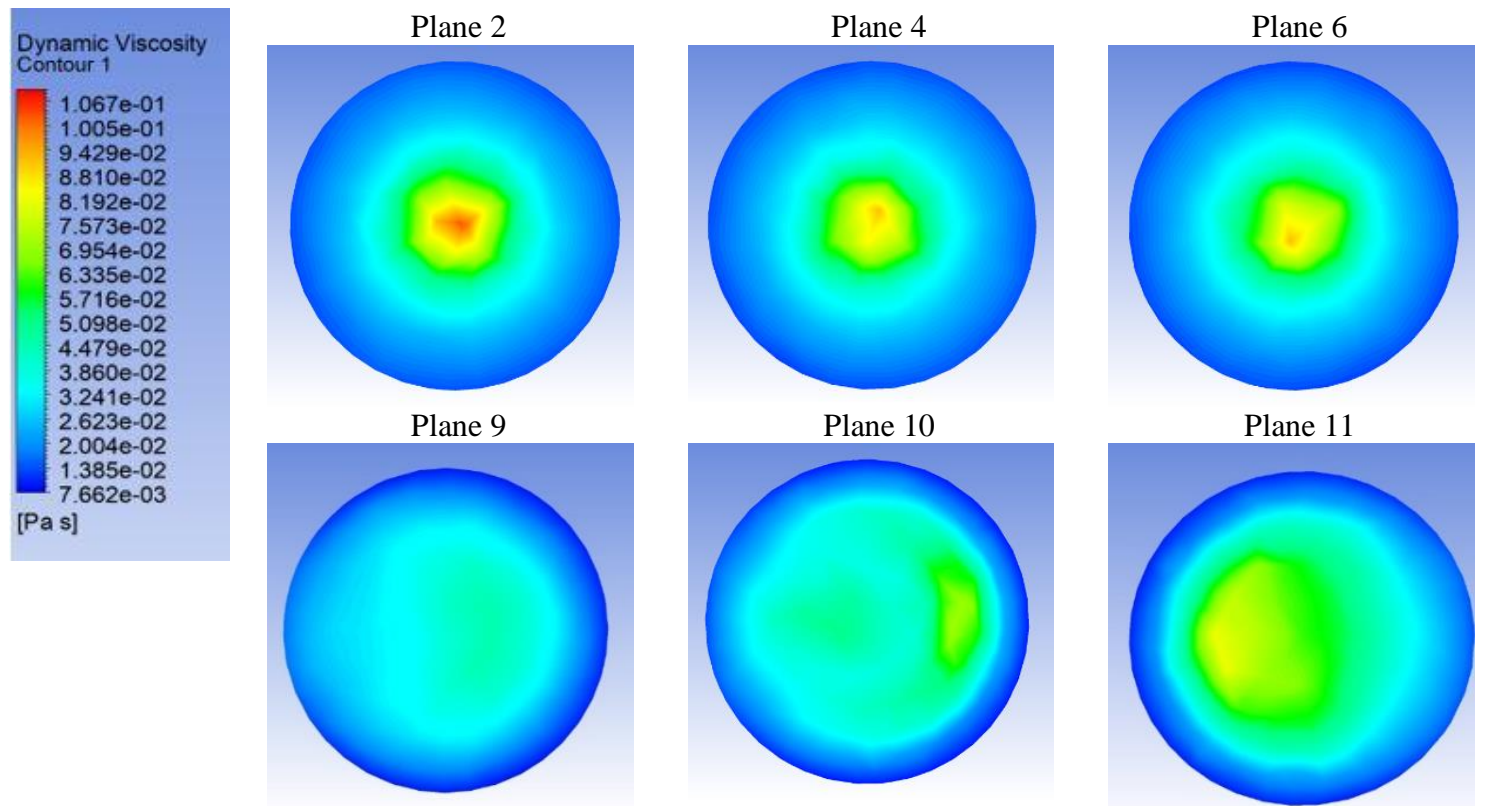

Figure 18. Dynamic viscosity at each plane location using fruit juice. 


\section{Conclusions}

This paper presents a 3D numerical simulation of the heat transfer process in a smooth curved tube heat exchanger. Water and fruit juice were used as working fluids to implement simulations under turbulent and laminar regime, respectively.

The differences between the temperature at the wall and the centre of the pipe for the fruit juice simulations were higher than for the water simulations. In addition, for the same constant heat flux condition, the difference between outlet temperature and inlet temperature was higher for the laminar simulation (approximately $4^{\circ} \mathrm{C}$ ) than for the turbulent one (approximately $0.7^{\circ} \mathrm{C}$ ). With regard to the fruit juice simulation, velocity variations were found along the elbow section. This is related to the centrifugal force acting on that section. At the inlet section and outlet section, velocity is uniform as it is not affected by the centrifugal forces.

The proposed numerical simulations are useful to analyse fluid viscosity along the computational domain. The pseudoplastic behaviour of the fruit juice used shows the fluid viscosity variability as a function of the shear rate. The activation energy obtained for the fruit juice did not yield high values, showing a moderate viscosity variation with the temperature change.

The simulations performed in this work are useful to analyse the behaviour of fluid foods in tubes as a prior step to designing heat exchangers to improve the heat transfer process. These tools, combined with the use of equipment to measure the rheology of fluid foods, is of great importance to the understanding of fluid flow in food processing.

Author Contributions: Conceptualisation, J.I.C.; Methodology, J.I.C., E.M.-A., and J.A.A.-I.; Software, J.I.C. and E.M.-A.; Validation, J.I.C. and E.M.-A.; Formal Analysis, J.I.C. and J.A.A.-I.; Investigation, J.I.C. and E.M.-A.; Resources, J.I.C. and J.A.A.-I.; Data-Curation, J.I.C.; Writing-Original Draft Preparation, J.I.C. and E.M.-A.; Writing-Review and Editing, J.I.C. and J.A.A.-I.; Visualisation, J.I.C., E.M.-A., and J.A.A.-I.; Supervision, J.I.C. and J.A.A.-I.; Project Administration, J.I.C. and J.A.A.-I.; and Funding Acquisition, J.I.C. and J.A.A.-I. All authors have read and agreed to the published version of the manuscript.

Funding: Provincial Council of Albacete and Project SBPLY/17/180501/000412 of the Regional Government of Castilla-La Mancha funded this work.

Acknowledgments: The authors wish to express their gratitude to the Provincial Council of Albacete, for providing funding and support for the project on the Analysis of the Behaviour of Food Industry Fluids in Heat Exchangers, making it possible to implement this study. Project SBPLY/17/180501/000412 of the Regional Government of Castilla-La Mancha also partially funded this work.

Conflicts of Interest: The authors declare no conflicts of interest.

\section{Notation}

$\begin{array}{ll}A & \text { Constant (Pa.s) } \\ a & \text { Tube inside radius (mm) } \\ C_{1}, C_{2}, C_{1 \varepsilon}, C_{3 \varepsilon} & k-\varepsilon \text { turbulence model constants } \\ C F D & \text { Computational Fluid Dynamics } \\ C_{f} & \text { Fanning friction factor } \\ C_{f_{c}} & \text { Fanning friction factor for curved tube } \\ C_{f_{s}} & \text { Fanning friction factor for straight tube } \\ C_{p} & \text { Specific heat }(\mathrm{J} /(\mathrm{kg} \mathrm{K})) \\ D & \text { Inner tube diameter }(\mathrm{m}) \\ \text { De } & \text { Dean number } \\ D_{h} & \text { Hydraulic diameter (m) } \\ E a & \text { Activation energy (kJ/mol) } \\ G_{b} & \text { Generation of turbulent kinetic energy due to buoyancy } \\ G_{k} & \text { Generation of turbulent kinetic energy due to the mean velocity gradients }\end{array}$




\begin{tabular}{|c|c|}
\hline$G z$ & Graetz number \\
\hline$h_{x}$ & Local heat transfer coefficient $\left(\mathrm{W} /\left(\mathrm{m}^{2} \mathrm{~K}\right)\right)$ \\
\hline HTF & Heat Transfer Fluid \\
\hline$I$ & Turbulent intensity (\%) \\
\hline K & Consistency index $\left(\mathrm{Pa} \cdot \mathrm{s}^{\mathrm{n}}\right)$ \\
\hline$K^{\prime}$ & Constant $\left(\mathrm{Pa} \cdot \mathrm{s}^{\mathrm{n}}\right)$ \\
\hline$K_{1}$ & Loss coefficient in a bend \\
\hline$L$ & Length (m) \\
\hline$L_{s}$ & Length of the straight tube $(\mathrm{m})$ \\
\hline$n$ & Flow behaviour index \\
\hline$N u$ & Average Nusselt number \\
\hline$N u_{c}$ & Nusselt for curved coil \\
\hline$N u_{s}$ & Nusselt for straight tube in turbulent regime \\
\hline$N u_{s_{l}}$ & Nusselt for straight tube in laminar regime \\
\hline$N u_{x}$ & Local Nusselt number \\
\hline$p$ & Pressure $(\mathrm{Pa})$ \\
\hline$P_{\text {outlet }}$ & Pressure outlet $(\mathrm{Pa})$ \\
\hline $\operatorname{Pr}$ & Prandtl number \\
\hline$P r_{t}$ & Turbulent Prandtl number \\
\hline$\dot{q}$ & Heat transfer flux $\left(\mathrm{W} / \mathrm{m}^{2}\right)$ \\
\hline$R$ & Radius of curvature (mm) \\
\hline $\operatorname{Re}$ & Reynolds number \\
\hline$R e_{g}$ & Generalised Reynolds number \\
\hline$R_{u}$ & Universal gas constant $(\mathrm{kJ} / \mathrm{mol} \mathrm{K})$ \\
\hline$S_{i j}$ & Deformation tensor \\
\hline$S_{r}$ & Mean strain-rate of the flow \\
\hline$S_{\varepsilon}$ & User-defined source term \\
\hline$S_{k}$ & User-defined source term \\
\hline$T$ & Temperature (K) \\
\hline$T_{f_{x}}$ & Average temperature of the fluid at position $x(\mathrm{~K})$ \\
\hline$T_{w_{x}}$ & Average inner wall temperature at position $x(\mathrm{~K})$ \\
\hline$u$ & Fluid velocity (m/s) \\
\hline$u_{T}$ & Friction velocity (m/s) \\
\hline$y^{+}$ & Dimensionless distance to the wall \\
\hline \multicolumn{2}{|c|}{ Greek symbols } \\
\hline$\Delta p_{b}$ & Pressure drop in a bend $(\mathrm{Pa})$ \\
\hline$\eta$ & Apparent viscosity $(\mathrm{Pa} \cdot \mathrm{s})$ \\
\hline$\Delta p$ & Pressure drop $(\mathrm{Pa})$ \\
\hline$\rho$ & Density $\left(\mathrm{kg} / \mathrm{m}^{3}\right)$ \\
\hline$\mu$ & Dynamic viscosity $(\mathrm{Pa} \cdot \mathrm{s})$ \\
\hline$\mu_{t}$ & Turbulent viscosity $(\mathrm{Pa} \cdot \mathrm{s})$ \\
\hline$\lambda$ & Thermal conductivity $(\mathrm{W} /(\mathrm{m} \mathrm{K}))$ \\
\hline$\lambda_{x}$ & Thermal conductivity at position $x(\mathrm{~W} /(\mathrm{m} \mathrm{K}))$ \\
\hline$\tau_{i j}$ & Viscous Stress Tensor \\
\hline$\sigma_{k}$ & Turbulence Prandtl number for $\mathrm{k}$ \\
\hline$\sigma_{\varepsilon}$ & Turbulence Prandtl number for $\varepsilon$ \\
\hline
\end{tabular}




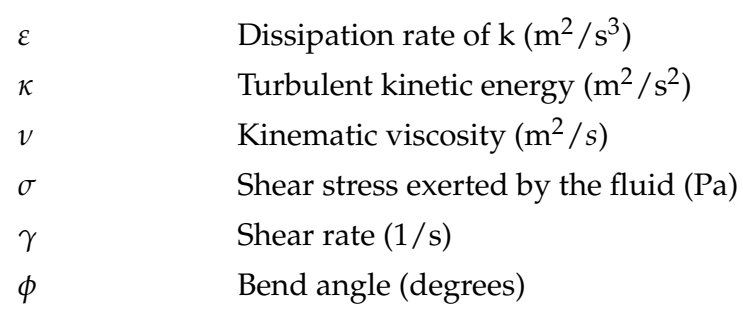

\section{Superscripts}

Fluctuating component

\section{Subscripts}

$\mathrm{i}, \mathrm{j}, \mathrm{k} \quad$ Direction of coordinate

\section{References}

1. Garakani, A.K.; Mostoufi, N.; Sadeghi, F.; Fatourechi, H.; Sarrafzadeh, M.; Mehrnia, M. Comparison between different models for rheological characterization of activated sludge. J. Environ. Health Sci. Eng. 2011, 8, 255-264.

2. Ibarz, A.; Falguera, V.; Garza, S.; Garvín, A. Rheology of redcurrant juices. Afinidad 2010, 67, $335-341$.

3. Chin, N.; Chan, S.; Yusof, Y.; Chuah, T.; Talib, R. Modelling of rheological behaviour of pummelo juice concentrates using master-curve. J. Food Eng. 2009, 93, 134-140. [CrossRef]

4. Belibağli, K.B.; Dalgic, A.C. Rheological properties of sour-cherry juice and concentrate. Int. J. Food Sci. Technol. 2007, 42, 773-776. [CrossRef]

5. Rozzi, S.; Massini, R.; Paciello, G.; Pagliarini, G.; Rainieri, S.; Trifiro, A. Heat treatment of fluid foods in a shell and tube heat exchanger: Comparison between smooth and helically corrugated wall tubes. J. Food Eng. 2007, 79, 249-254. [CrossRef]

6. Liebenberg, L.; Meyer, J.P. In-tube passive heat transfer enhancement in the process industry. Appl. Therm. Eng. 2007, 27, 2713-2726. [CrossRef]

7. Kareem, Z.S.; Jaafar, M.M.; Lazim, T.M.; Abdullah, S.; Abdulwahid, A.F. Passive heat transfer enhancement review in corrugation. Exp. Therm. Fluid Sci. 2015, 68, 22-38. [CrossRef]

8. Seban, R.; McLaughlin, E. Heat transfer in tube coils with laminar and turbulent flow. Int. J. Heat Mass Transf. 1963, 6, 387-395. [CrossRef]

9. Pawar, S.; Sunnapwar, V.K.; Mujawar, B. A critical review of heat transfer through helical coils of circular cross section. J. Sci. Ind. Res. 2011, 10, 835-843.

10. Mori, Y.; Nakayama, W. Study of forced convective heat transfer in curved pipes (2nd report, turbulent region). Int. J. Heat Mass Transf. 1967, 10, 37-59. [CrossRef]

11. Rajasekharan, S.; Kubair, V.; Kuloor, N. Heat transfer to non-Newtonian fluids in coiled pipes in laminar flow. Int. J. Heat Mass Transf. 1970, 13, 1583-1594. [CrossRef]

12. Rao, B. Turbulent heat transfer to power-law fluids in helical passages. Int. J. Heat Fluid Flow 1994, 15, 142-148. [CrossRef]

13. Mujawar, B.A.; Roa, M.R. Flow of Non-Newtonian Fluids through Helical Coils. Ind. Eng. Chem. Process Des. Dev. 1978, 17, 22-27. [CrossRef]

14. Mashelkar, R.; Devarajan, G. Secondary flows of non-Newtonian fluids: Part I-Laminar boundary layer flow of a generalized non-Newtonian fluid in a coiled tube. Trans. Inst. Chem. Eng. 1976, 54, 100-107.

15. Gratão, A.; Silveira, V., Jr.; Telis-Romero, J. Laminar forced convection to a pseudoplastic fluid food in circular and annular ducts. Int. Commun. Heat Mass Transf. 2006, 33, 451-457. [CrossRef]

16. Marn, J.; Ternik, P. Laminar flow of a shear-thickening fluid in a 90 pipe bend. Fluid Dyn. Res. 2006, 38, 295-312. [CrossRef]

17. Manzar, M.; Shah, S. Particle distribution and erosion during the flow of Newtonian and non-Newtonian slurries in straight and coiled pipes. Eng. Appl. Comput. Fluid Mech. 2009, 3, 296-320. [CrossRef]

18. Pawar, S.; Sunnapwar, V.K. Experimental and CFD investigation of convective heat transfer in helically coiled tube heat exchanger. Chem. Eng. Res. Des. 2014, 92, 2294-2312. [CrossRef] 
19. Mirgolbabaei, H.; Taherian, H.; Domairry, G.; Ghorbani, N. Numerical estimation of mixed convection heat transfer in vertical helically coiled tube heat exchangers. Int. J. Numer. Methods Fluids 2011, 66, 805-819. [CrossRef]

20. Bandyopadhyay, T.; Das, S. Non-Newtonian and gas-non-newtonian liquid flow through elbows-CFD analysis. J. Appl. Fluid Mech. 2013, 6, 131-141.

21. Fluent, I.A. User Guide; ANSYS Inc.: Canonsburg, PA, USA, 2019.

22. Ağra, Ö.; Demir, H.; Atayılmaz, Ş.Ö.; Kantaş, F.; Dalkılıç, A.S. Numerical investigation of heat transfer and pressure drop in enhanced tubes. Int. Commun. Heat Mass Transf. 2011, 38, 1384-1391. [CrossRef]

23. Córcoles-Tendero, J.; Belmonte, J.; Molina, A.; Almendros-Ibáñez, J. Numerical simulation of the heat transfer process in a corrugated tube. Int. J. Therm. Sci. 2018, 126, 125-136. [CrossRef]

24. Salim, S.M.; Cheah, S. Wall $\mathrm{y}^{+}$strategy for dealing with wall-bounded turbulent flows. In Proceedings of the International Multiconference of Engineers and Computer Scientists, Hongkong, China, 18-20 March 2009; Volume 2, pp. 2165-2170.

25. Han, H.; Li, B.; Shao, W. Effect of flow direction for flow and heat transfer characteristics in outward convex asymmetrical corrugated tubes. Int. J. Heat Mass Transf. 2016, 92, 1236-1251. [CrossRef]

26. Córcoles, J.; Belmonte, J.; Molina, A.; Almendros-Ibáñez, J. Influence of corrugation shape on heat transfer performance in corrugated tubes using numerical simulations. Int. J. Therm. Sci. 2019, 137, 262-275. [CrossRef]

27. White, F.M. Fluid Mechanics; McGraw Hill: New York, NY, USA, 2008.

28. Petukhov, B. Heat transfer and friction in turbulent pipe flow with variable physical properties. In Advances in Heat Transfer; Elsevier: Amsterdam, The Netherlands, 1970; Volume 6, pp. 503-564.

29. Metzner, A.; Reed, J. Flow of non-newtonian fluids, correlation of the laminar, transition, and turbulent-flow regions. Aiche J. 1955, 1, 434-440. [CrossRef]

30. Crespí-Llorens, D.; Vicente, P.; Viedma, A. Generalized Reynolds number and viscosity definitions for non-Newtonian fluid flow in ducts of non-uniform cross-section. Exp. Therm. Fluid Sci. 2015, 64, 125-133. [CrossRef]

31. Jayakumar, J.; Mahajani, S.; Mandal, J.; Vijayan, P.; Bhoi, R. Experimental and CFD estimation of heat transfer in helically coiled heat exchangers. Chem. Eng. Res. Des. 2008, 86, 221-232. [CrossRef]

32. Chang, T.H. An investigation of heat transfer characteristics of swirling flow in a 180 circular section bend with uniform heat flux. KSME Int. J. 2003, 17, 1520-1532. [CrossRef]

33. Besserman, D.; Tanrikut, S. Comparison of heat transfer measurements with computations for turbulent flow around a 180 degree bend. In ASME 1991 International Gas Turbine and Aeroengine Congress and Exposition; American Society of Mechanical Engineers: Orlando, FL, USA, 1991; pp. 865-871.

34. Rogers, G.; Mayhew, Y. Heat transfer and pressure loss in helically coiled tubes with turbulent flow. Int. J. Heat Mass Transf. 1964, 7, 1207-1216. [CrossRef]

35. Xin, R.; Ebadian, M. The effects of Prandtl numbers on local and average convective heat transfer characteristics in helical pipes. J. Heat Transf. 1997, 119, 467-473. [CrossRef]

36. Shah, R.K.; Joshi, S.D. Convective heat transfer in curved ducts. In Handbook of Single-Phase Convective Heat Transfer; John Wiley and Sons Inc.: New York, NY, USA, 1987; pp. 5-8.

37. Kakaç, S.; Liu, H.; Pramuanjaroenkij, A. Heat Exchangers: Selection, Rating, and Thermal Design; CRC Press: Boca Raton, FL, USA, 2002.

38. Itō, H. Friction factors for turbulent flow in curved pipes. J. Basic Eng. 1959, 81, 123-132. [CrossRef]

39. Di Liberto, M.; Ciofalo, M. A study of turbulent heat transfer in curved pipes by numerical simulation. Int. J. Heat Mass Transf. 2013, 59, 112-125. [CrossRef]

40. Di Piazza, I.; Ciofalo, M. Transition to turbulence in toroidal pipes. J. Fluid Mech. 2011, 687, $72-117$. [CrossRef]

41. Nellis, G.; Klein, S. Heat Transfer; Cambridge University Press: New York, NY, USA, 2009.

(C) 2020 by the authors. Licensee MDPI, Basel, Switzerland. This article is an open access article distributed under the terms and conditions of the Creative Commons Attribution (CC BY) license (http:/ / creativecommons.org/licenses/by/4.0/). 